\title{
$\alpha$-Latrotoxin Alters Spontaneous and Depolarization-Evoked Quantal Release from Rat Adrenal Chromaffin Cells: Evidence for Multiple Modes of Action
}

\author{
Jun Liu and Stanley Misler \\ Departments of Medicine and Cell Biology/Physiology and Program in Neuroscience, Washington University, \\ St. Louis, Missouri 63110
}

$\alpha$-Latrotoxin ( $\alpha$-LT) potently enhances both "spontaneous" and "depolarization-evoked" quantal secretion from neurons. Here we have used the patch-clamped rat adrenal chromaffin cell to examine simultaneously the effects of $\alpha$-LT on membrane current or voltage, cytosolic $\mathrm{Ca}$, and membrane capacitance, the latter used as an assay for exocytosis. In chromaffin cells exposed to toxin concentrations of $>100 \mathrm{pm}$, the development of large conductance, Ca-permeable ion channels, accompanied by a rise in cytosolic Ca to levels near $1 \mu \mathrm{M}$, precedes the initiation of spontaneous exocytosis. These channels appear to be induced de novo, because they occur concurrently with massive reduction or pharmacological block of voltage-

$\alpha$-Latrotoxin (a-LT), a $130 \mathrm{kDa}$ peptide derived from the venom of the black widow spider, is a potent excitatory neurotoxin that selectively binds to vertebrate presynaptic nerve terminals to produce skeletal muscle twitching followed by slow progressive muscle paralysis (Rosenthal and Meldolesi, 1989). Within minutes of its application to an isolated neuromuscular junction, at picomolar concentrations, the toxin initially increases action potential-evoked quantal release as well as "spontaneous" quantal release of transmitter. However, over time, the toxin often blocks nerve terminal conduction and "depolarization-evoked" release (Longenecker et al., 1970; Hurlbut and Ceccarelli, 1979). Two proposed mechanisms of $\alpha$-LT action, each involving the binding of toxin to membrane receptor(s), might underlie these actions. (1) Binding of $\alpha$-LT to its receptor(s) might serve to anchor the toxin to the plasma membrane, thus enabling it to form $\mathrm{Ca}$ permeable, nonselective cation channels through which $\mathrm{Ca}^{2+}$ and other divalent cations may enter the nerve terminal (Finkelstein et al., 1976; Misler and Hurlbut, 1979; Meldolesi et al., 1983). (2) Binding of $\alpha$-LT to its receptor(s) might alter the interaction of that receptor with intracellular protein(s) involved with docking or fusion of secretory granules with the plasma membrane (Petrenko et al., 1991; Petrenko, 1993). Currently there are two candidate receptors, and each has been shown to interact, in vitro,

\footnotetext{
Received April 15, 1998; revised May 28, 1998; accepted June 1, 1998.

This work was supported by the Barnes-Jewish Hospital Research Foundation and the National Institutes of Health Grant DK37380. We thank Dr. Alexander Petrenko for the gift of purified toxin, Dr. David Barnett for the design and continuing refinement of our recording setup, and Dr. Kevin Gillis for invaluable advice.

Correspondence should be addressed to Dr. Stanley Misler, Renal Division (Yalem 815), Barnes-Jewish Hospital-North, 216 South Kingshighway, St. Louis, MO 63110.

We dedicate this paper as a "Festschrift" to Dr. William P. Hurlbut, a pioneer in latrotoxin research.

Copyright (ㄷ) 1998 Society for Neuroscience $\quad 0270-6474 / 98 / 186113-13 \$ 05.00 / 0$
}

dependent $\mathrm{Na}$ and $\mathrm{Ca}$ currents. However, enhancement of depolarization-evoked release, seen in many cells at $<50 \mathrm{pm}$ toxin, often occurs in the absence of a rise in background cytosolic $\mathrm{Ca}$ or de novo channel activity. These results favor $\mathrm{Ca}$ entry through toxin-induced channels underlying initiation of spontaneous release and direct modulation of the secretory machinery by the toxin-bound receptor contributing to enhancement of depolarization-evoked secretion as well as spontaneous release.

Key words: neurotoxin; exocytosis; membrane capacitance; amperometry; cytosolic Ca; catecholamines with a component of the secretory apparatus. A Ca-dependent receptor that resembles neurexin binds synaptotagmin, a putative Ca sensor (Petrenko et al., 1991; Ushkaryov et al., 1992); a Ca-independent receptor (CIRL/latrophilin) (Davletov et al., 1996; Krasnoperov et al., 1996) that resembles members of a family of G-protein-coupled membrane receptors binds to syntaxin, a putative component of the vesicle-docking complex (Bennett and Scheller, 1994).

Using amperometry (Wightman et al., 1991; Chow et al., 1992) and membrane capacitance tracking (Neher and Marty, 1982; Augustine and Neher, 1992) as single-cell assays of exocytosis, we have demonstrated previously that crude black widow spider venom and purified $\alpha$-LT cause massive quantal release from rat adrenal medullary chromaffin cells (Zhou and Misler, 1995; Barnett et al., 1996; Liu and Misler, 1998). These neural crestderived, excitable endocrine cells are often used as a model system to study the mechanisms of exocytosis at nerve terminals as well as the roles of neurotoxins in modifying transmitter release (e.g., Bittner et al., 1989). One set of experiments reported here offers direct evidence strongly supporting the hypothesis that toxin-induced "channel formation" and the attendant rise in cytosolic $\mathrm{Ca}$ are critical for initiation of spontaneous exocytosis. Another set of experiments suggests that the enhancement of depolarization-evoked release, seen at lower doses of toxin, may result from an "alternative" action of the toxin that is independent of its ability to enhance cytosolic $\mathrm{Ca}$. It is likely that the latter action results from the ability of a toxin-bound receptor to modify the intrinsic machinery of the secretory apparatus. This alternative action may substantially enhance the potency of channel formation-based, toxin-related spontaneous exocytosis.

Parts of this paper have been published previously (Liu and Misler, 1998a). 


\section{MATERIALS AND METHODS}

\section{Preparation of cells}

Freshly harvested rat adrenals were defatted, decorticated, minced, and enzymatically digested with a cocktail of collagenase $\mathrm{D}$, hyaluronidase type 1, and DNase type 1 using a protocol described elsewhere (Neely and Lingle, 1992; Liu and Misler, 1998). The resulting cells were plated on coverslips coated with Matrigel (Becton Dickinson, Rutherford, NJ) and maintained for up to $5 \mathrm{~d}$ in a $95 \%$ air $/ 5 \% \mathrm{CO}_{2}$ incubator at $37^{\circ} \mathrm{C}$ using a DMEM (Life Technologies, Gaithersburg, MD) enriched with $10 \%$ fetal bovine serum, $100 \mathrm{IU} / \mathrm{ml}$ penicillin, $100 \mathrm{mg} / \mathrm{ml}$ streptomycin, and $6 \mathrm{mg} / \mathrm{ml}$ ascorbic acid and buffered with HEPES and $\mathrm{HCO}_{3}{ }^{-}$. Fura-2 AM was loaded into cells; cells were incubated for $20 \mathrm{~min}$ in the dark at room temperature in HEPES-buffered DMEM containing fura-2 AM $(5 \mu \mathrm{M})$ and then were washed for 20 min with DMEM plus $10 \%$ FBS to permit de-esterification of the dye. This approach provided uniform loading of the cytoplasm with the Ca-sensitive dye and levels of photon emission approximately fivefold greater than the autofluorescence.

\section{Preparation and application of toxin}

Purified $\alpha$-LT (2-3 $\mu \mathrm{M}$ stock) was the gift of Dr. Alexandre Petrenko (New York University). The toxin was diluted to a $1 \mu \mathrm{M}$ stock, stored at $4^{\circ} \mathrm{C}$, and then further diluted, as needed, on the day of use. Aliquots were injected into the $1.8 \mathrm{ml}$ capacity bath from a micropipetter whose tip was $\sim 5-8 \mathrm{~mm}$ from the recording pipette; the tip was then used to gently agitate the bath to promote convection. The toxin concentrations reported (20 pм to $2 \mathrm{nM}$ ) were calculated "equilibrium concentrations" (i.e., amount injected/bath volume), presumed to be reached within 3 min after injection.

\section{Recordings}

Three to five days after their isolation and plating, single rat chromaffin cells were monitored at room temperature $\left(20-23^{\circ} \mathrm{C}\right)$ in a HEPESbuffered physiological saline solution (PSS) containing (in mM): 145 $\mathrm{NaCl}, 5.5 \mathrm{KCl}, 2 \mathrm{CaCl}_{2}, 0.1 \mathrm{MgCl}_{2}, 10$ glucose, and 20 HEPES titrated to $\mathrm{pH} 7.3$ with $\mathrm{NaOH}$. In experiments in which $\mathrm{Ca}$ currents were measured, $35 \mathrm{~mm} \mathrm{NaCl}$ was replaced mole-for-mole with tetraethylammonium chloride (TEA). A "Ca-free" PSS was made by eliminating $\mathrm{CaCl}_{2}$ from, and adding $1 \mathrm{~mm}$ EGTA to, the control PSS. An "isotonic$\mathrm{Ca}$ " PSS was made by replacing the $\mathrm{NaCl}$ content of PSS with $98 \mathrm{~mm}$ $\mathrm{CaCl}_{2}$. Other customized solutions are described in the text.

Electrophysiological recordings. Electrophysiological recordings were made using a perforated-patch variant of the whole-cell recording standard for our lab (Barnett et al., 1996). For voltage-clamp recording, patch pipettes and salt bridges in contact with the indifferent $\mathrm{Ag} / \mathrm{AgCl}$ electrode were filled with a standard high $\mathrm{Cs}$ internal solution containing (in $\mathrm{mm}$ ): $63.7 \mathrm{CsCl}, 28.35 \mathrm{Cs}_{2} \mathrm{SO}_{4}, 47.2$ sucrose, $11.8 \mathrm{NaCl}, 1 \mathrm{MgCl}_{2}$, and 20 HEPES titrated to 7.3 with $\mathrm{KOH}$. A similar solution containing 3-5 $\mu \mathrm{l}$ of nystatin $(250 \mu \mathrm{g} / \mathrm{ml})$ was added just proximal to the tip of the patch pipette. The membrane potential was held at $-70 \mathrm{mV}$ throughout the experiment, and sinusoidal, square pulse, or ramp voltage excitation $(-100$ to $+60 \mathrm{mV}$ over $100 \mathrm{msec}$ or -50 to $+50 \mathrm{mV}$ over $3 \mathrm{sec})$ was imposed as needed. In experiments in which zero current potentials were sought, liquid junction potentials were calculated using standard ion mobilities (Barry and Lynch, 1991) and appropriately added algebraically to interpret individual results (Barry and Lynch, 1991; Neher, 1992). For current-clamp experiments, a high $\mathrm{K}$ internal solution, in which $\mathrm{CsCl}$ and $\mathrm{Cs}_{2} \mathrm{SO}_{4}$ were replaced mole-for-mole by $\mathrm{KCl}$ and $\mathrm{K}_{2} \mathrm{SO}_{4}$, respectively, was used to fill the pipette. Current and voltage traces were filtered at 0.5 and $1.5 \mathrm{KHz}$, respectively, and sampled at $3 \mathrm{KHz}$.

Our setup for data acquisition and processing has been described in detail previously (Barnett and Misler, 1997). In experiments in which capacitance and current were monitored simultaneously, the circuit parameters of the patch-clamped cell, namely, the parallel combination of membrane resistance $\left(R_{m}\right)$ and capacitance $\left(C_{m}\right)$ in series with the pipette-to-cytoplasm access resistance $\left(R_{a}\right)$, were estimated using an EPC-9 patch-clamp amplifier (Heka Electronic, Lambrecht, Germany) and a newly described software-based, dual frequency lock-in detector (LID). The LID was developed as a set of extensions (XOP modules) to the numerical/graphics package Igor (Wavemetrics). The program was run on a Macintosh Quadra-650 (Apple). Samples of the analog current signal were acquired using an ITC-16 analog-to-digital card (Instrutech, Syosset, NY). Appropriately filtered sinusoidal stimulation $(10 \mathrm{mV}$ peakto-peak at 400 and $800 \mathrm{~Hz}$ ) was applied to the patch-clamp amplifier held at a DC potential of $-70 \mathrm{mV}$. The resultant membrane current signal at each frequency, which is phase shifted from the input voltage signal, was fed into the LID that decomposes the current signal into real (or in-phase) and imaginary (or quadrature) components of the admittance. Based on these four measurements, a nonlinear weighted least squares algorithm is used to estimate the circuit parameters $\left(R_{m}, C_{m}\right.$, and $\left.R_{a}\right)$, which are subsequently displayed in real time. The DC membrane current $\left(I_{m}\right)$ at $-70 \mathrm{mV}$, estimated by averaging the sampled current over the period of the lower frequency sine wave (i.e., $2.5 \mathrm{msec}$ ), is also displayed to track background channel activity. By interrupting the sinusoidal excitation with square steps of depolarization, it is possible to examine depolarization-evoked exocytosis as well. Recently this program has been modified by Dr. David W. Barnett to trigger a monochrometer and to collect and display the output of a photomultiplier tube (Till Photonics Photometrics System; Applied Scientific Instruments, Eugene, OR), thereby permitting synchronous ratiometric determination of cytosolic $\mathrm{Ca}$ in cells loaded with fura-2.

Amperometric recordings. Amperometric recordings were performed with polypropylene-insulated carbon fiber electrodes touching the cell surface and held at $+780 \mathrm{mV}$ using an EPC-7 amplifier (Heka Electronic) (Zhou and Misler, 1996). Amperometric data, filtered at $300 \mathrm{~Hz}$ using an eight-pole Bessel filter (Frequency Devices, Haverhill, MA), were acquired simultaneously with membrane current or membrane voltage data using the software package that runs the digital LID. Amperometric events were reviewed and tabulated with an interactive Igor-based program in use in our lab. The criteria for scoring an amperometric event were (1) an amplitude of at least $1 \mathrm{pA}$ (approximately three times the peak-to-peak background noise of acceptable recordings) and (2) a half-height duration of at least $2 \mathrm{msec}$.

\section{Ratiometric monitoring of cytosolic $\mathrm{Ca}$}

Cytosolic $\mathrm{Ca}$ was estimated from ratiometric measurements made on cells loaded with fura-2. Loaded cells were mounted on the stage of an inverted epifluorescence microscope outfitted for dual wavelength (340 and $380 \mathrm{~nm}$ ) excitation and appropriate throughput of fluorescence emission via a bandpass dichroic mirror $(500-520 \mathrm{~nm})$. Optical slits were set to collect emission from a single cell. Average ratiometric data were converted to cytosolic $\mathrm{Ca}$ estimates $\left([\mathrm{Ca}]_{\mathrm{i}}\right)$ using the equation: $[\mathrm{Ca}]_{\mathrm{i}}=$ $224 \mathrm{nM}\left(R-R_{\min }\right) /\left(R_{\max }-R\right) \times\left(F_{380, \text { max }} / F_{380, \text { min }}\right)$, where $R_{\max }$ and $F_{380, \text { max }}$ and then $R_{\min }$ and $F_{380 \text {,min }}$ were obtained sequentially after first adding $5 \mu \mathrm{M}$ ionomycin and then $2.5 \mathrm{~mm}$ EGTA to the bath (Grynkiewicz et al., 1985).

\section{RESULTS}

\section{Basic phenomenology of $\alpha$-LT action on chromaffin cells}

In previous experiments using amperometry (Liu and Misler, 1998b), we examined key features of toxin action in promoting catecholamine secretion from rat adrenal chromaffin cells. These include (1) its threshold concentration of $\sim 30 \mathrm{pm}$ and saturating dose of $\sim 1 \mathrm{nM},(2)$ its requirement of extracellular $\mathrm{Ca}$ in the micromolar range for secretory action but not "functional" binding, and (3) the association of its secretagogue action with a rise in cytosolic $\mathrm{Ca}$ to $\sim 1 \mu \mathrm{M}$ but not with the functional state of endogenous $\mathrm{Ca}$ channels. Because these results primarily resembled those produced by toxin at nerve terminals, they encouraged us to use the chromaffin cell as a model system to examine features of toxin action not amenable to investigation at the nerve terminal. Specifically, we examined the relationship of the channel-forming action of the toxin to its ability to enhance spontaneous and depolarization-evoked exocytosis.

\section{Comparison of the time courses of toxin-induced channel activity, capacitance increases, and quantal releases of catecholamines}

From our previous experiments on patch-clamped chromaffin cells, in which exocytosis was measured by membrane capacitance tracking, it seemed that the progressive development of toxininduced channel activity was followed by the onset of exocytosis measured as an increase in $C_{m}$. Furthermore, the initial time 

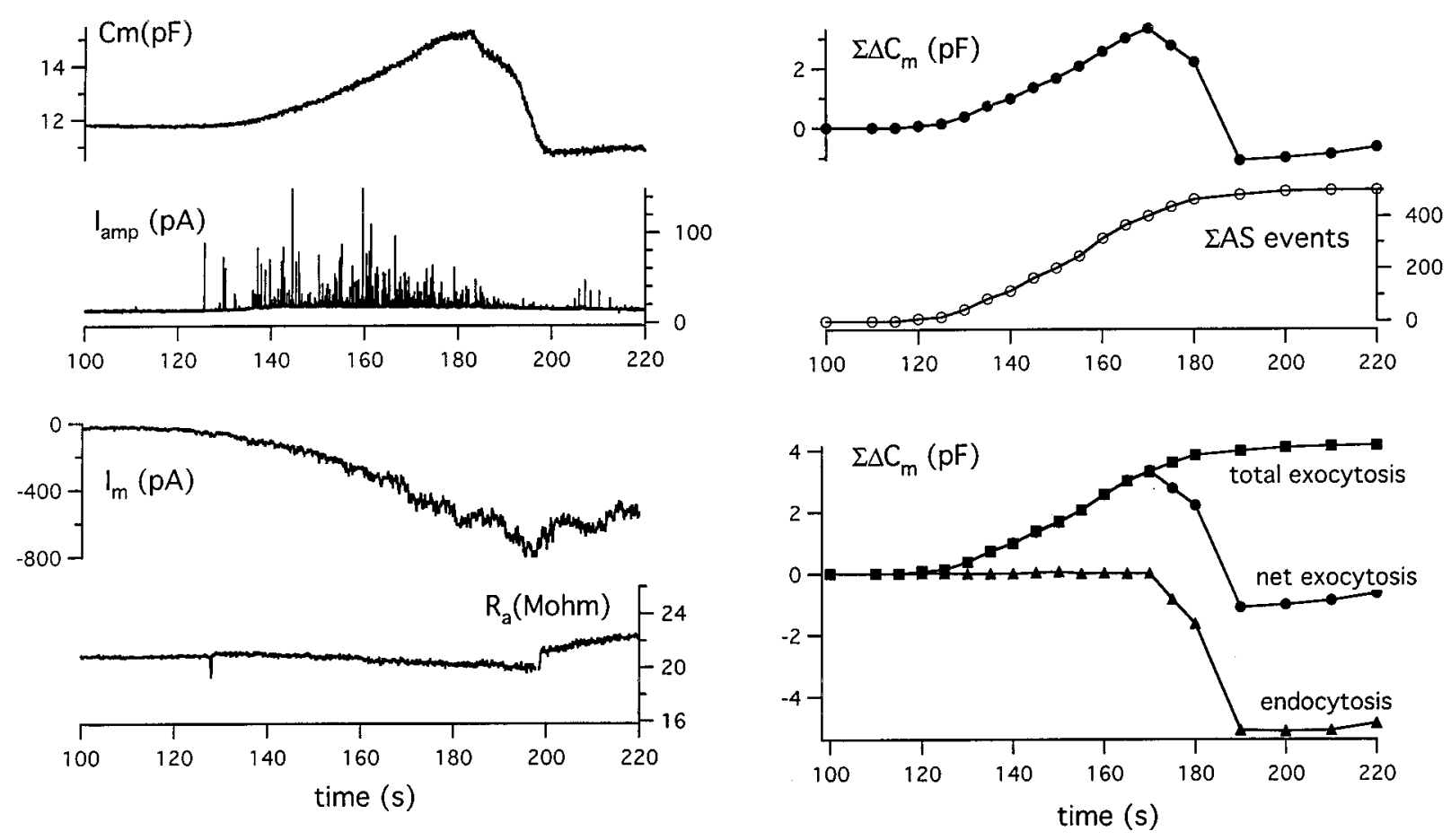

Figure 1. Simultaneous monitoring of secretory response to $\alpha$-LT by capacitance tracking and amperometry permits estimation of time courses of exocytosis and endocytosis. Left, Time courses of membrane capacitance $\left(C_{m}\right)$, amperometric current events $\left(I_{\text {amp }}\right)$, membrane current $\left(I_{m}\right)$, and access resistance $\left(R_{a}\right)$ recorded from patch-clamped chromaffin cells held at $-70 \mathrm{mV}$ beginning $30 \mathrm{sec}$ after the addition of $500 \mathrm{pM} \alpha$-LT to the bath. Note that $R_{a}$ remained stable throughout the depicted time interval, thus reducing chances of a "cross-talk" artifact between changing membrane resistance and $C_{m}$, especially when membrane resistance is $<100 \mathrm{M} \Omega$. Upper Right, Comparison of time course of $\Delta C_{m}$ and the running sum of amperometrically detected quantal release events. Lower Right, Estimates of time course of total exocytosis, net exocytosis, and endocytosis after addition of toxin. See Results for details of computation.

course of $C_{m}$ increase was similar to the initial time course of toxin-induced quantal release, measured amperometrically from nonpatch-clamped cells (Barnett et al., 1996). To bridge these two techniques, we performed a set of experiments in which both assays of exocytosis were monitored simultaneously on the same patch-clamped cells.

Figure 1 (left) displays simultaneous traces of membrane capacitance $\left(C_{m}\right)$, amperometric current $\left(I_{\mathrm{amp}}\right)$, and membrane current $\left(I_{m}\right)$, as well as the pipette-to-cytoplasm access resistance $\left(R_{a}\right)$. Channel activity began $\sim 30 \mathrm{sec}$ after toxin application. A detectable increase in $C_{m}$, as well as the onset of amperometric spike events (ASs), was first appreciated $25 \mathrm{sec}$ after channel activity began, by which time at least $50 \mathrm{pA}$ of inward current had developed. Thereafter, both the frequency of amperometric events and the rate of rise in membrane capacitance rapidly increased. $C_{m}$ peaked at $2.5 \mathrm{pF}$ above baseline within a minute of commencement of release, a time when amperometric discharge was still vigorous and toxin-induced current was still increasing. However, $C_{m}$ dropped off over the next $20 \mathrm{sec}$, in fact undershooting control values by $>1 \mathrm{pF}$.

Figure 1 (right) provides stricter quantitation and an approach to the interpretation of this data. The upper panel demonstrates the similar time courses of cumulative development of $C_{m}$ $\left(\Sigma \Delta C_{m}\right)$ and ASs ( $\left.\Sigma \mathrm{AS}\right)$. If we assume that each amperometric event corresponds to the fusion with the plasma membrane of a granule that is $300-350 \mathrm{~nm}$ in diameter and has a unitary capacitance equaling $2.4 \mathrm{fF}$ (Chow et al., 1994), the ratio $(\Sigma \mathrm{AS} \times 2.4$ $\mathrm{fF} / \mathrm{AS}) /\left(\right.$ observed $\left.\Sigma \Delta C_{m}\right)$ is nearly constant at $0.283( \pm 0.02)$ over $60 \mathrm{sec}$. (A similar ratio was seen in this cell on comparing $\Sigma$ AS with $\Sigma \Delta C_{m}$ during repetitive depolarization.) The lower panel of
Figure 1 demonstrates that scaling $\Sigma$ AS by the factor $(2.4 \mathrm{fF} /$ AS $\times 1 / 0.283)$ produces a curve of calculated $\Sigma \Delta C_{m}$ versus time; for the initial $60 \mathrm{sec}$, this calculated curve is virtually superimposable on the curve of observed $\Sigma \Delta C_{m}$ versus time. On this basis we designate the observed $\Sigma \Delta C_{m}$ versus time trace as "net exocytosis," the calculated $\Sigma \Delta C_{m}$ versus time trace as "total exocytosis," and the time course of the difference between the two curves as "endocytosis."

Altogether, the results presented in Figure 1, representative of those in a series of three similar experiments performed at room temperature (and one at $30^{\circ} \mathrm{C}$ ), strongly support two ideas. First, amperometry and the capacitance tracking are monitoring exocytosis from the same pool of granules, although amperometry is less efficient because it is monitoring release from a limited area of cell surface. This confirmed our initial prediction that the dual sinusoidal excitation technique for capacitance estimation is robust enough to track exocytosis even in the face of major changes in membrane conductance (Barnett and Misler, 1997). In addition, the intense amperometric discharge was associated with little or no slow DC displacement of the baseline. The latter might suggest contamination of the record by a cloud of background release from multiple small granules. Second, in the presence of the toxin, initial vigorous exocytosis can be followed by slow and then more rapid endocytosis that serves to retrieve the plasma membrane and restore its surface area to near the resting value. The rapid component of endocytosis occurs at a rate of $\sim 0.4$ $\mathrm{pF} / \mathrm{sec}$ and actually results in a $10 \%$ undershoot in $C_{m}$. This component resembles the "excess retrieval" mode of endocytosis seen with massive depolarization-induced $\mathrm{Ca}$ entry sufficient to raise cytosolic $\mathrm{Ca}$ to $\sim 10 \mu \mathrm{M}$ even in cells from which recordings 
were made in the perforated-patch mode (Artalejo et al., 1995; Smith and Neher, 1997).

\section{Relationship of toxin-induced channel activity and spontaneous exocytosis}

In a previous study examining the dependence of toxin action on external $\mathrm{Ca}$, we found that crude venom gland extract massively increased the resting membrane current and conductance of chromaffin cells held at $-70 \mathrm{mV}$, whether they were bathed in control PSS or a very low Ca (10-20 $\mu \mathrm{M})$ PSS, although the latter solution did not support exocytosis. In the very low Ca PSS, the background current developed in a stepwise manner, suggesting the appearance of long duration, large conductance channels, whereas in control PSS, the current developed in a more "ragged" manner with very few discrete steps. We suggested that the toxin might form large conductance, nonselective cation channels and that $\mathrm{Ca}$ interacts with these channels as a "permeant blocker," permeating yet tightly binding within the channel pore (Barnett et al., 1996). To characterize toxin-induced currents more carefully, we applied doses of purified toxin that, based on our recent dose-response secretion studies using amperometry (Liu and Misler, 1998a), might allow us to capture initial single-channel activity as well as subsequent larger increases in membrane current as the toxin-induced channels dominate membrane conductance. These experiments were performed using continuous whole-cell voltage-clamp recording, combined with intermittent voltage-ramp stimulation, on cells bathed in solutions of varying composition.

\section{Development of a massive toxin-induced current occurs in the presence of a drastic reduction in endogenous voltage- dependent calcium and sodium currents}

To examine toxin-induced currents in chromaffin cells, we attempted initially to block endogenous voltage-dependent currents. Figure $2 A$ shows results from an experiment (typical of a set of three) in which a cell, bathed in a PSS containing $35 \mathrm{~mm}$ TEA, was patched with a $\mathrm{Cs}^{+}$-nystatin pipette. Under these conditions, in which the majority of voltage- and $\mathrm{Ca}$-dependent $\mathrm{K}^{+}$currents are blocked, a 100-msec-long voltage ramp (from -100 to $+60 \mathrm{mV}$ ) evokes two components of inward current, namely, an initial spike, peaking at $-20 \mathrm{mV}$, and a later shoulder, most prominent at $0 \mathrm{mV}$. Addition of $1 \mu \mathrm{M}$ tetrodotoxin (TTX), a potent $\mathrm{Na}$ channel blocker, and $200 \mu \mathrm{M} \mathrm{Cd}$, a potent $\mathrm{Ca}$ channel blocker, abolishes both components of inward current and further reduces outward current. Subsequent addition of toxin produces a slowly developing background current that is inward at -70 $\mathrm{mV}$, is mildly outwardly rectifying, and has an average zero current potential $\left(E_{\text {rev }}\right)$ of $+3 \mathrm{mV}$ (or $-5 \mathrm{mV}$ after correction of liquid junction potential). Figure $2 B$ shows results (typical of a set of four) from a variant of the latter experiment in which a cell, bathed in a PSS containing $5 \mathrm{~mm}$ TEA and $4 \mu \mathrm{M}$ apamin, a more-specific blocker of the small conductance $\mathrm{Ca}$-dependent $\mathrm{K}^{+}$ currents prominently displayed by these cells, was patched with a $\mathrm{Cs}^{+}$-nystatin pipette. Under these conditions, in which the voltage-dependent inward current is initially intact, addition of toxin results in the apparent disappearance of both the spike and shoulder components, concurrent with the development of a background current that here is nearly linear with voltage and has an $E_{\mathrm{rev}}$ of $+8 \mathrm{mV}$ (or $-1 \mathrm{mV}$ after correction of liquid junction potential). Continuation of the electrical recording reveals that the background current slowly wanes, and thereafter both components of the voltage-dependent current return.
The ability of the toxin to induce a large membrane conductance under conditions in which voltage-dependent currents are blocked, as well as to drastically reduce or abolish the latter currents reversibly, suggests that toxin-induced current is flowing through "novel" channels rather than through altered "native" ones. The ability of the toxin to block voltage-dependent currents necessary for excitability most likely underlies its capacity, over time, to depress depolarization-evoked release, a key feature of its effect at presynaptic terminals.

\section{Toxin-induced channels are generally permeable to cations including calcium}

Figure 3 examines the ionic selectivity of the toxin-induced membrane conductance. Figure $3 A$ provides evidence that this conductance is overwhelmingly cation-selective. In three paired experiments, we compared the current-voltage $(I-V)$ relationships obtained after applying 200-500 pM toxin in a Ca-free PSS (with $1 \mu \mathrm{M}$ TTX and $5 \mathrm{mM}$ TEA) with those obtained after applying toxin in a modified $\mathrm{Ca}$-free PSS in which approximately one-half of the $\mathrm{NaCl}(65 \mathrm{~mm})$ was isosmotically replaced with sucrose. Partial $\mathrm{NaCl}$ replacement shifted the observed $E_{\mathrm{rev}}$ by -15 to $-18 \mathrm{mV}$, consistent with nearly ideal cation selectivity of the toxin-induced conductance. Figure $3 B$ provides evidence that large univalent cations are at least somewhat permeable through this conductance pathway. This $I-V$ curve was typical of those obtained in three cells after addition of toxin to a Ca-free PSS in which all of the total $\mathrm{Na}+\mathrm{K}$ content but $3 \mathrm{~mm}$ was replaced with the bulky univalent cation $N$-methyl-D-glucamine (NMDG). Note that substantial toxin-induced inward current is still seen at potentials negative to -5 to $-10 \mathrm{mV}$, although outward rectification is now prominent. Figure $3 C$ provides evidence that $\mathrm{Ca}$ is highly permeable through this conductance as well. Note that after addition of toxin to isotonic-Ca PSS (residual [ $\mathrm{Na}]_{\mathrm{o}}$ of $<3 \mathrm{~mm}$ ), impressive inward current is seen at voltages negative to $0 \mathrm{mV}$; in fact, the $I-V$ curve is nearly linear. Altogether these results suggest that toxin-induced channels are cation-permeable but poorly "selective" among cations, in part because of their large pore diameter.

As illustrated in Figure 4, in several cells it was possible to record under varying ionic conditions, for up to $10 \mathrm{sec}$, clearly recognizable single-channel events before the onset of massive membrane current. This allowed us to examine our hypothesis that $\mathrm{Ca}$ acts as a permeant blocker of toxin-induced channels. In cells voltage clamped at $-70 \mathrm{mV}$, inward current steps, up to 10 sec long and averaging $30 \mathrm{pA}$ in amplitude, were seen in Ca-free PSS; using the observed $E_{\mathrm{rev}}$ of +5 to $+8 \mathrm{mV}$, we estimate a single-channel conductance $(\gamma)$ of $\sim 400 \mathrm{pS}$. In contrast, smaller, more "flickery" openings, averaging $20 \mathrm{pA}$ in amplitude and never exceeding $0.3 \mathrm{sec}$ in duration, were seen in control PSS (containing $2 \mathrm{~mm} \mathrm{Ca}$ ); from these data we calculated $\gamma$ to be $\sim 270$ $\mathrm{pS}$. In two out of six cells examined, clear single-channel openings were seen in isotonic-Ca PSS; the majority of these averaged 10 pA in amplitude and appeared to occur as clusters of openings; from these data we calculated $\gamma$ to be $\sim 130 \mathrm{pS}$.

\section{Toxin-enhanced spontaneous quantal release is dependent on $\mathrm{Ca}$ entry and cytosolic Ca accumulation}

Our early experiments showed that the onset of exocytosis follows progressive development of toxin-induced channel activity only if adequate external calcium is present. These results suggested that $\mathrm{Ca}$ entry through the large conductance channels, with a subsequent accumulation in the cytosol, is critical in 
(A)
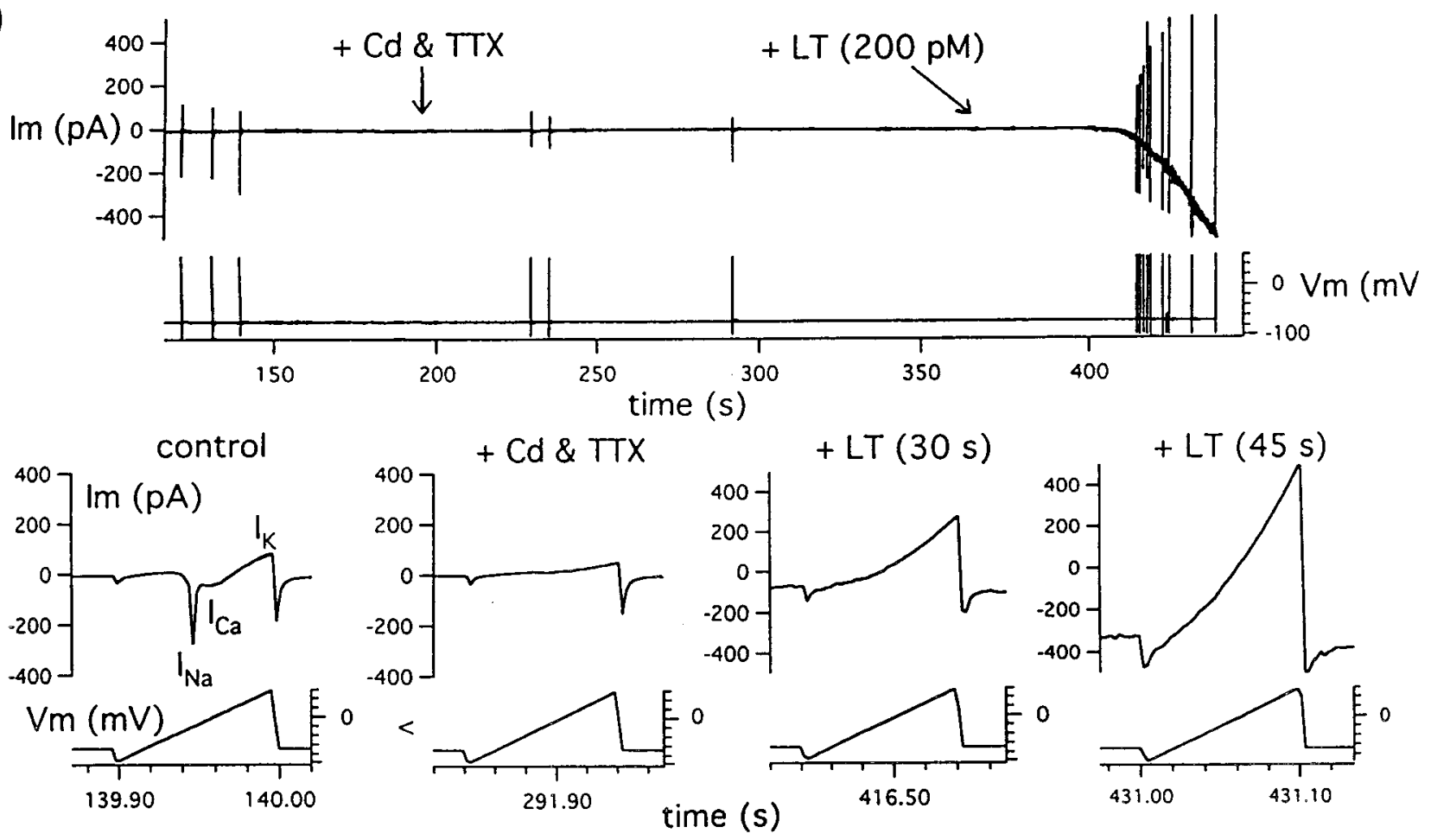

(B)
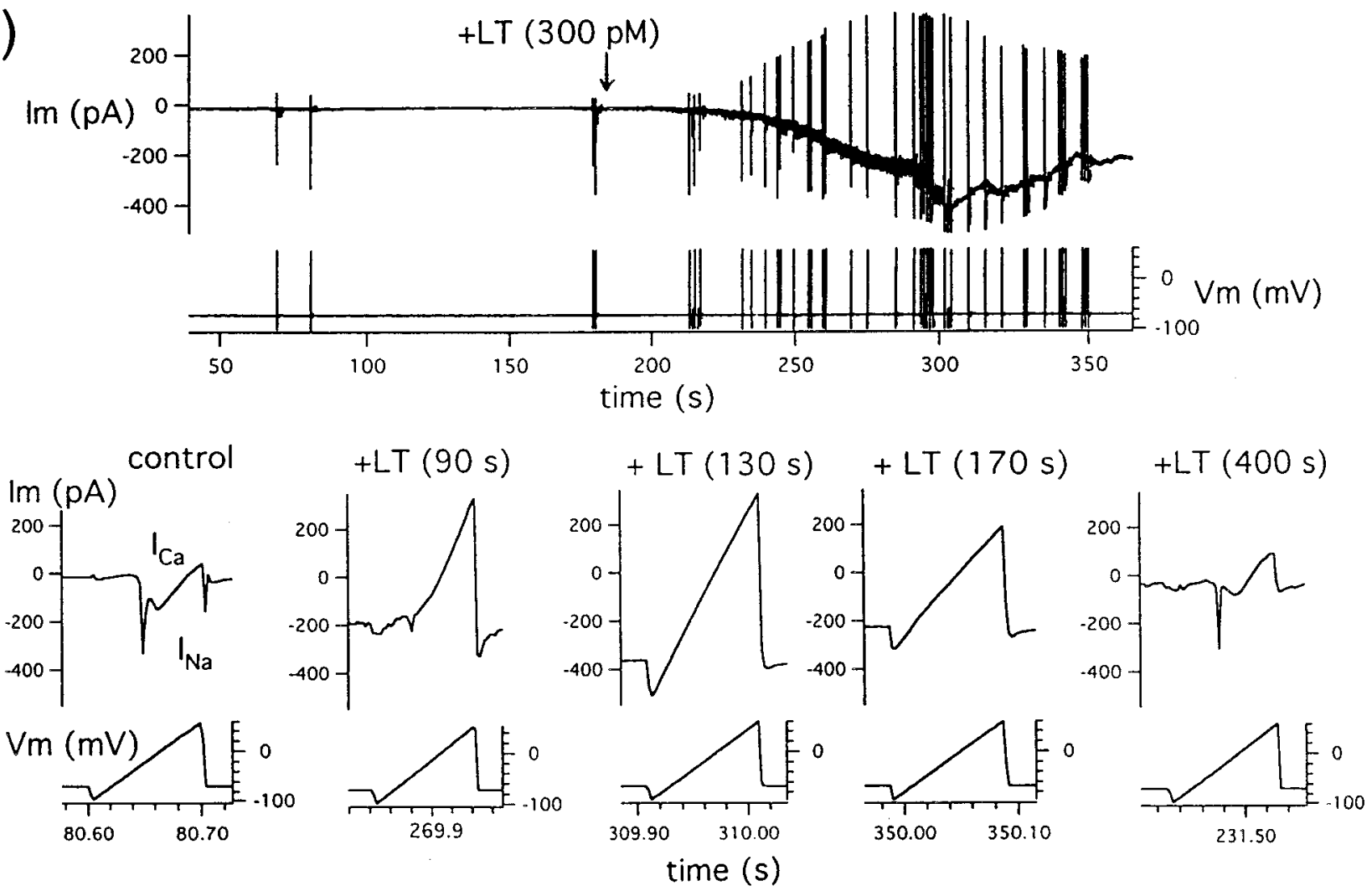

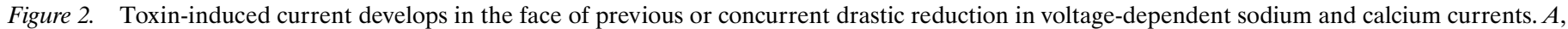

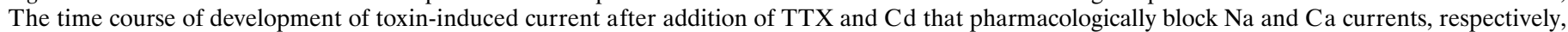

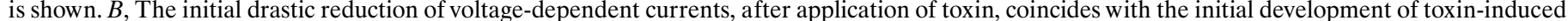

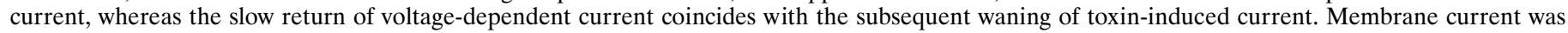

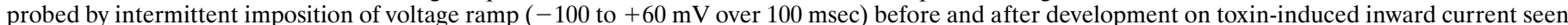

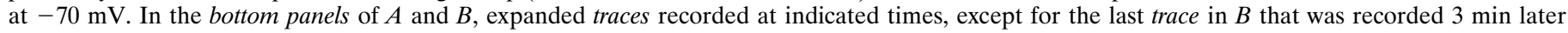
as part of a different data file, are presented. 
(A)

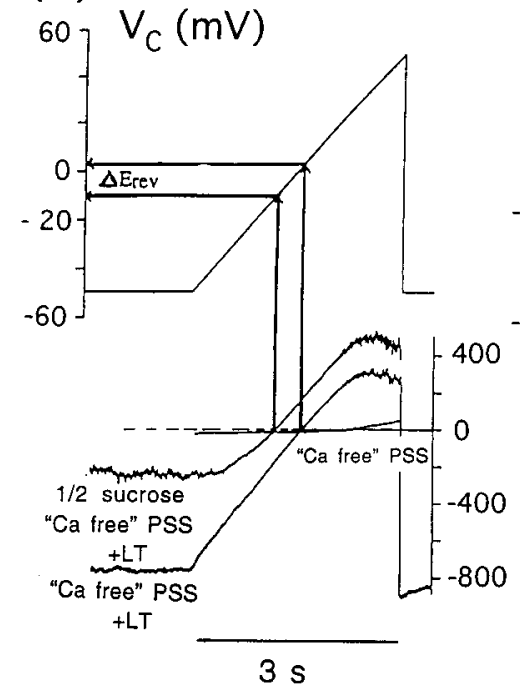

(B)

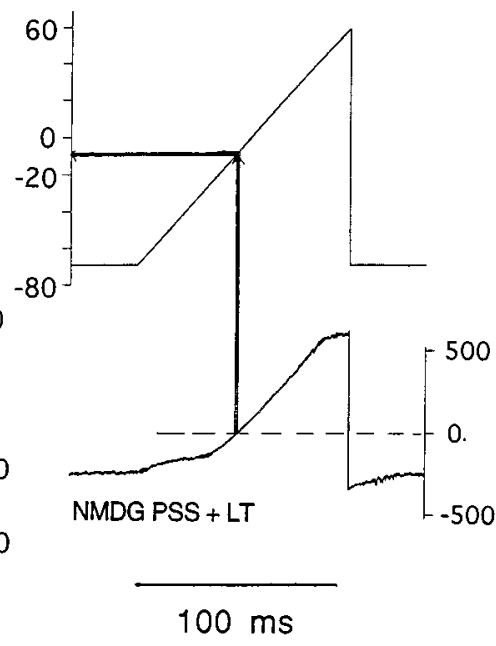

(C)

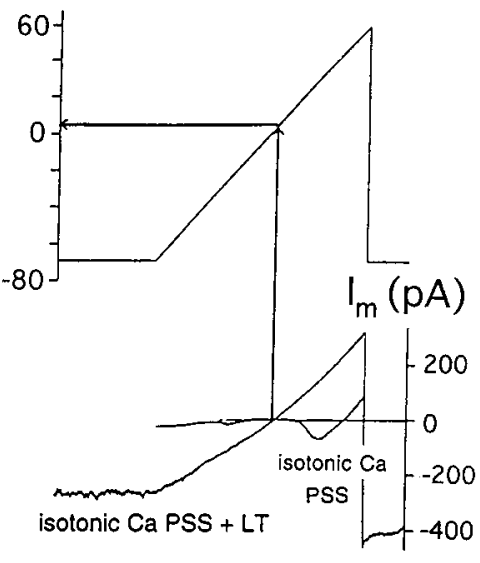

$100 \mathrm{~ms}$

Figure 3. Survey of ion permeability via $\alpha$-LT-induced membrane conductance. Currents were recorded in response to voltage ramps $60-90$ sec after the application of toxin to different cells bathed in Ca-free PSS and in modified Ca-free PSS in which 65 mM NaCl was replaced isosmotically with sucrose $(A)$, in Ca-free PSS in which Na and $\mathrm{K}$ (all but $3 \mathrm{mM}$ ) were replaced with NMDG $(B)$, and in isotonic-Ca PSS $(C)$. See Results for general overview. Two specific points deserve clarification. (1) Current-voltage relationships seen before application of toxin are shown for Ca-free PSS and isotonic-Ca PSS to eliminate nonspecific effects in these unusual solutions. The lack of voltage-dependent Ca current in Ca-free PSS is attributed to an external Ca of $<10 \mu \mathrm{M}$; the lack of Na current is attributed to a partial block by TTX and partial inactivation by a maintained holding potential of $-50 \mathrm{mV}$. After toxin application, the "turn-down" in outward current at very positive membrane potentials may reflect closure of toxin channels through a flickery subconductance state. Such a phenomenon was observed after application of the $10 \mathrm{~nm}$ toxin to one side of a lipid bilayer bathed in $150 \mathrm{~mm} \mathrm{KCl}$ (W. German and S. Misler, unpublished observations). In the isotonic-Ca PSS, note that voltage-dependent Ca current peaks at approximately $+30 \mathrm{mV}$, because of the elevated bath $\mathrm{Ca}$ and shifts in the activation curve of the high voltage-activated Ca channels. (2) $E_{\text {rev }}$ denotes the observed reversal potential of toxin-induced current in each condition. Because in each case, the liquid junction potentials (LJP) were zeroed before patching the cell, the shift in $E_{\mathrm{rev}}$ can be used to assess the relative permeability of ions, although in each case we calculate that the observed $E_{\mathrm{rev}}$ is shifted positively by $8 \mathrm{mV}$ from the true $E_{\text {rev }}$ because of partial undoing of the LJP correction after seal formation.

$$
\begin{gathered}
\text { Single channel currents } \\
\qquad V_{m}=-70 \mathrm{mV}
\end{gathered}
$$

"Ca free" PSS

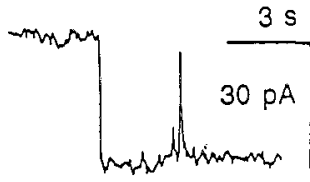

control PSS
Figure 4. Single-channel currents induced by the toxin. Left, Sample traces of the first distinct signs of toxininduced channel activity recorded after toxin application at a holding potential of $-70 \mathrm{mV}$ in three ionic conditions: Ca-free PSS, control PSS, and isotonic-Ca PSS. Right, Histogram of single-channel current amplitudes recorded under these three conditions.

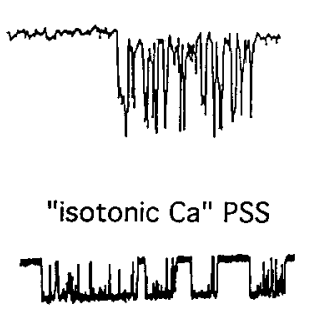

evoking exocytosis. If this suggestion is reasonable, then (1) before the onset of release, cytosolic $\mathrm{Ca}$ should rise to levels seen with other conditions, such as cell dialysis or membrane permeabilization (Dunn and Holz, 1983; Augustine and Neher, 1992), that evoke sustained release, and (2) raising the extracellular $\mathrm{Ca}^{2+}$ concentration should increase the effectiveness of each increment in current to provoke release. Figure 5 shows that these predictions are borne out experimentally.

Figure 5, $A$ and $B$, compares the time courses of toxin-induced

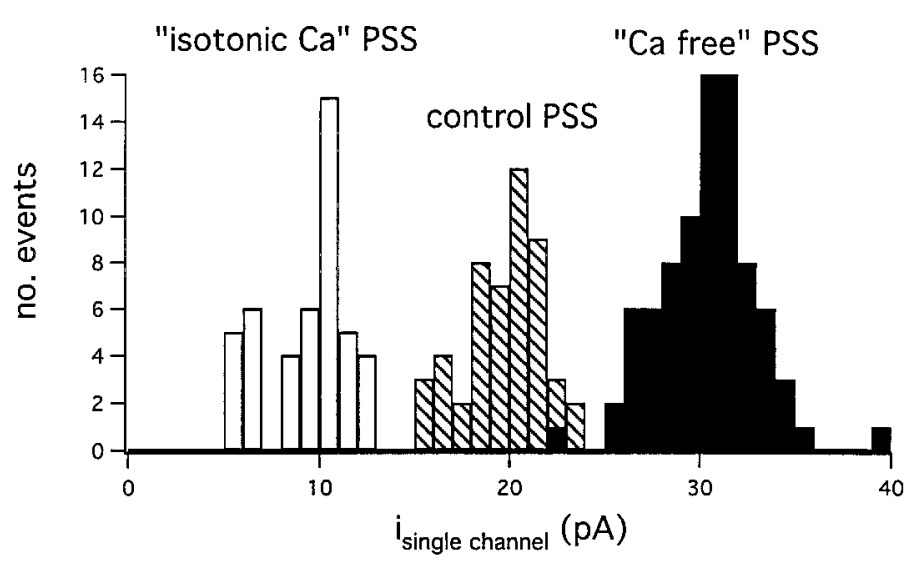

membrane current, the rise in cytosolic $\mathrm{Ca}$, and the development of exocytotic release in patch-clamped, fura-2-loaded cells bathed in control PSS (2 mm Ca) or isotonic-Ca PSS (98 mm Ca). These records, which are each representative of a set of four cells, indicate that under both conditions (1) development of toxininduced channel activity precedes the rise in cytosolic $\mathrm{Ca}$ and (2) a rise in estimated cytosolic $\mathrm{Ca}$ to $0.5-1 \mu \mathrm{M}$ precedes the onset of a clear rise in membrane capacitance. However, as predicted above, with isotonic-Ca PSS, the threshold level of cytosolic $\mathrm{Ca}$ is 

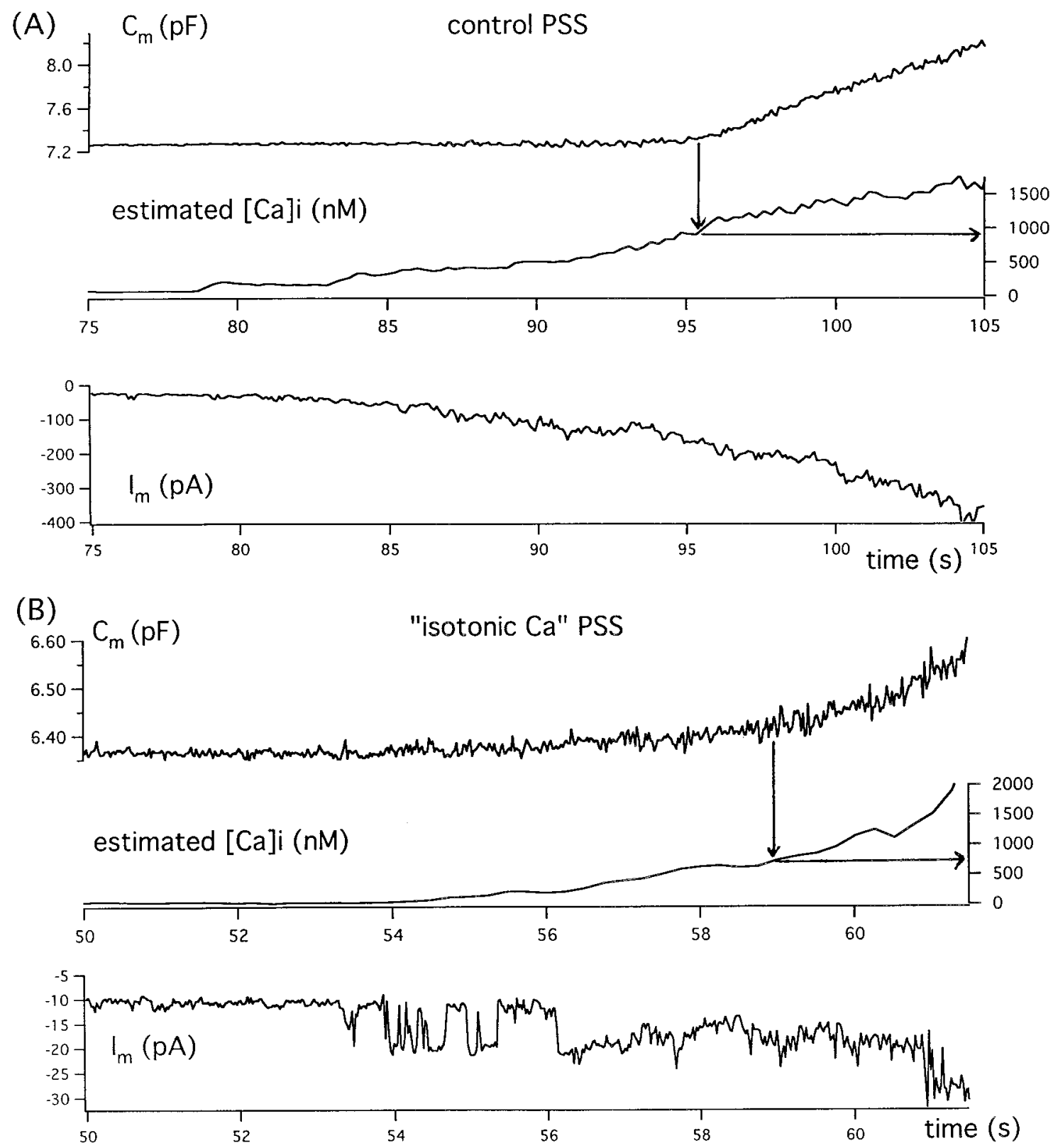

Figure 5. Temporal relationship of toxin-induced exocytosis, measured as an increase in membrane capacitance, to toxin-induced channel activity and the rise in cytosolic Ca seen at near-physiological versus near-isotonic extracellular Ca concentrations. $A$, Results obtained in control PSS after addition of $200 \mathrm{~nm}$ toxin at $30 \mathrm{sec} . B$, Results obtained in isotonic-Ca PSS after addition of $200 \mathrm{~nm}$ toxin at 20 sec. Note that in both ionic conditions, the onset of exocytosis (noted by an arrow) follows a rise in cytosolic $\mathrm{Ca}$ to $\sim 1 \mu \mathrm{M}$. However, membrane current flow and total charge transfer preceding this rise are clearly many fold greater in control PSS than in isotonic-Ca PSS.

reached after currents as low as $10 \mathrm{pA}$ flow for $5 \mathrm{sec}$, whereas with standard PSS, the threshold level of cytosolic $\mathrm{Ca}$ is reached only after an average current flow of nearly $100 \mathrm{pA}$ for 15 sec.

\section{Timing of $\alpha-L T$-induced depolarization and release}

Since the discovery that $\alpha$-LT increases cation permeability of membranes, it has been assumed that the ability of $\alpha$-LT to induce spontaneous quantal release involves, in part, its ability to depolarize secretory terminals and to set off electrical activity (Longenecker et al., 1970; Nicholls et al., 1982). Figure 6, taken from combined current-clamp and amperometry experiments, presents direct evidence that $\alpha$-LT indeed depolarizes chromaffin cells and sets off a barrage of action potentials before the onset of quantal release, whereas the slow-to-start quantal release persists long after electrical activity is blocked. The first signs of toxin activity are small, discrete steps of depolarization, probably corresponding to the induction of single channels, beginning $40 \mathrm{sec}$ after application of toxin. (In these cells with a background membrane resistance of $\sim 0.75 \mathrm{G} \Omega$, an inward current of $20 \mathrm{pA}$ should produce a $15 \mathrm{mV}$ depolarization.) Subsequent progressive depolarization drives the membrane potential to the threshold for evoking action potentials of increasing frequency and then to a prolonged plateau phase, approaching $0 \mathrm{mV}$. The latter phase is consistent with the massive, prolonged opening of nonselective 


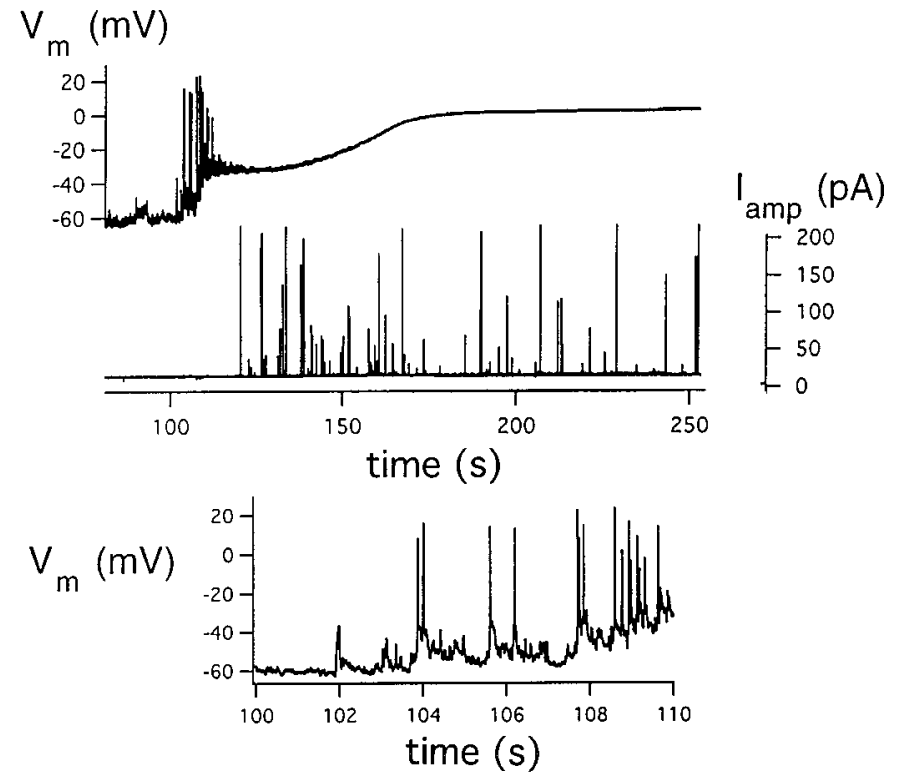

Figure 6. Time course of membrane excitability and quantal release of current-clamped chromaffin cells treated with toxin. Top, Simultaneous recordings of membrane potential $\left(\mathrm{V}_{\mathrm{m}}\right)$ and amperometric currents $\left(I_{\mathrm{amp}}\right)$ beginning $10 \mathrm{sec}$ after application of $150 \mathrm{pm}$ toxin. Bottom, Expanded $\mathrm{V}_{\mathrm{m}}$ trace over the interval in which electrical activity commences.

cation channels and the depolarization-induced inactivation of native voltage-dependent channels. Note that quantal release is first detectable near the conclusion of the initial barrage of action potentials and continues for the duration of plateau depolarization. In some cells tested, very low doses of toxin (30-50 pM) evoke infrequent barrages of action potentials that are occasionally accompanied by brief bursts of amperometric spikes.

\section{Enhancement by toxin of depolarization-evoked secretion}

At nerve terminals, small doses of $\alpha$-LT often enhance impulseevoked quantal release by several fold before the onset of massive increases in spontaneous quantal release. We sought a parallel phenomenon in chromaffin cells to apply patch-clamp recording to dissect out candidate mechanisms underlying it. We found that low concentrations of toxin, which do not enhance spontaneous exocytosis, do enhance depolarization-evoked release.

In experiments presented in Figure 7, we compared the capacitance increases $\left(\Delta C_{m}\right)$ in response to a brief "test train" of 10 membrane depolarizations (100- or 200-msec-long pulses from -70 to $+10 \mathrm{mV}$ applied at $1 \mathrm{~Hz}$ ) applied at intervals to control cells and to test cells exposed to $20-50 \mathrm{pm}$ toxin. In Figure $7 A$, note that in four out of four control cells, identical test trains of membrane depolarization produced, at most, a 1.15-fold increase in $\Delta C_{m}$ over $15 \mathrm{~min}$, whereas depolarization-evoked Ca current changed by $<10 \%$. In contrast in Figure $7 B$, note that after addition of toxin, 9 out of 14 cells tested displayed substantial enhancement of depolarization-evoked $\Delta C_{m}$, despite a $<10 \%$ change in depolarization-evoked $\mathrm{Ca}$ entry measured as peak $\mathrm{Ca}$ currents or the summed integrals of the current. The enhancement of $\Delta C_{m}$ averaged 1.85 -fold over $10 \mathrm{~min}$ and 2.15-fold over 15 min. Data from a sample experiment are shown in Figure $7 C$. These experiments established that low concentrations of the toxin can support increases in depolarization-evoked release out of proportion to any changes in Ca current.
We considered three mechanisms by which toxin might increase depolarization-evoked exocytosis in the presence of nearly constant depolarization-evoked Ca entry. First, toxin might continuously and substantially enhance background cytosolic $\mathrm{Ca}$ by producing low-frequency channel activity. Given that activation of depolarization-evoked release (Engisch and Nowycky, 1996) and the proposed $\mathrm{Ca}$ sensor synaptotagmin (Bennett and Scheller, 1994; Littleton and Bellen, 1995) both appear to require the binding of more than one $\mathrm{Ca}$ ion, background $\mathrm{Ca}$ that is subthreshold for evoking exocytosis by itself might however significantly modulate the cytosolic $\mathrm{Ca}$ level achieved after a constant pulse of $\mathrm{Ca}$ entry. Second, intermittent bursts of toxinrelated channel activity or release of $\mathrm{Ca}$ from organelle stores might transiently raise average cytosolic $\mathrm{Ca}$ to $300-500 \mathrm{~nm}$ for several seconds, a situation known to potentiate evoked release for up to tens of seconds even after background cytosolic $\mathrm{Ca}$ has returned to baseline (Heinemann et al., 1993; von Rueden and Neher, 1993). Third, the toxin might enhance secretion without inducing any rise in cytosolic $\mathrm{Ca}$. Toxin-bound receptors might interact with a component of the secretory apparatus, thereby directly enhancing Ca-sensitive exocytosis.

Experiments combining spectrofluorimetry with capacitance tracking in fura-2-loaded cells allow us to distinguish the relative roles of these proposed mechanisms. Two basic scenarios were observed. (1) In six out of eight experiments, during the 7-12 $\mathrm{min}$ after addition of 30-50 pM toxin, on average we measured a 2.5 -fold $( \pm 0.4 \mathrm{SD})$ increase in depolarization-evoked exocytosis above baseline. In all cases this occurred with a $<5 \%$ rise in estimated background cytosolic $\mathrm{Ca}$ and a $<7 \%$ rise in peak cytosolic $\mathrm{Ca}$ estimated to occur during the depolarization train (for example, compare Fig. 8, left and middle columns). If we assume a power of 1.5-3 dependence of quantal release on cytosolic Ca (Augustine and Neher, 1992; Heinemann et al., 1993; Engisch and Nowycky, 1996), a 7\% increase in peak cytosolic Ca should produce at most a 1.23 -fold increase in evoked release. These considerations favor a mechanism that does not require sustained enhancement of cytosolic $\mathrm{Ca}$. In addition, during the recording periods, which included $\sim 30 \%$ of the entire interval between trains, we were unable to detect toxin-induced channel activity in the background current or an enhanced frequency of brief spontaneous cytosolic $\mathrm{Ca}$ transients that is sometimes seen in these cells. Although we cannot eliminate the possibility of $\mathrm{Ca}$ entry during nonrecorded periods, in three out of the six cells we observed stable augmentation of $\Delta C_{m}$ for several determinations in the absence of interval changes in background cytosolic $\mathrm{Ca}$ or $\mathrm{Ca}$ handling. Altogether these data make a mechanism of continuous enhancement of depolarization-evoked release that is independent of a toxin-induced rise in cytosolic $\mathrm{Ca}$ more plausible than a mechanism of intermittent enhancement of depolarization-evoked release involving bursts of Ca entry. (2) In contrast, in three out of the eight cells, brief exposure (3-8 min in two cells) or more prolonged exposure (12 min in another cell; see Fig. 8, right column) to toxin resulted in a rise in background to a level of several hundred nanomolar. Under these conditions, we observed the largest toxin-induced increments in evoked release (averaging fourfold). However these increases were accompanied by intermittent inward current pulses $\sim 20$ pA in amplitude. In addition, in two experiments the half-times for recovery of cytosolic $\mathrm{Ca}$ were prolonged by a factor of nearly 2.5 . The latter observations suggest that steady-state, low-grade channel activity and altered cytosolic $\mathrm{Ca}$ handling can contribute to enhancement of release by toxin. 
(A) control cells

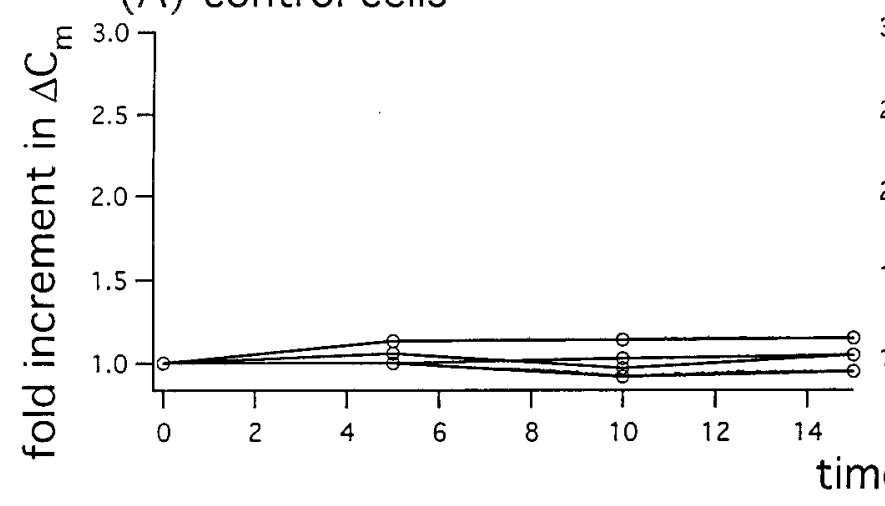

(C)

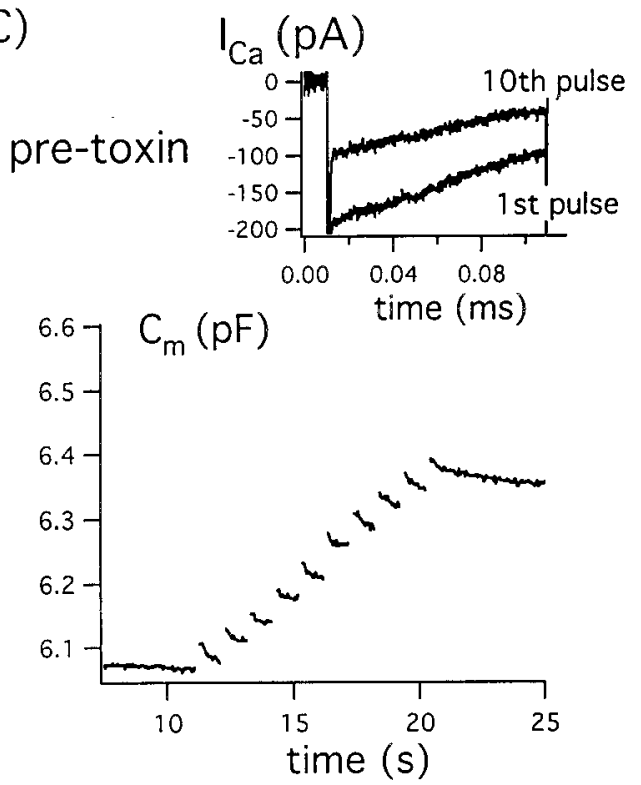

(B) cells exposed to $20-50 \mathrm{pM}$

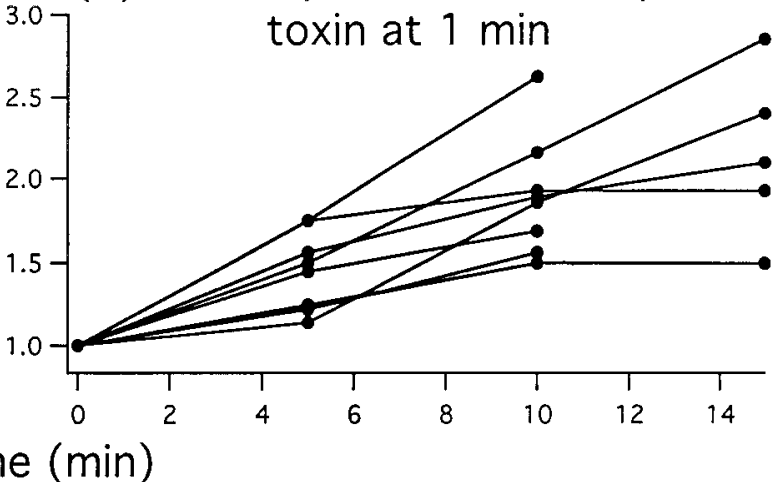

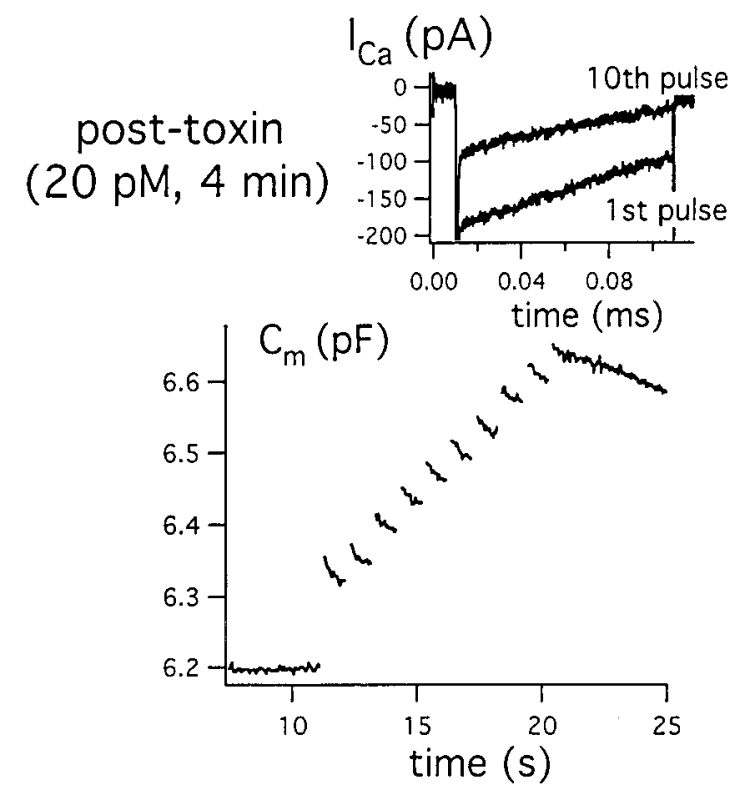

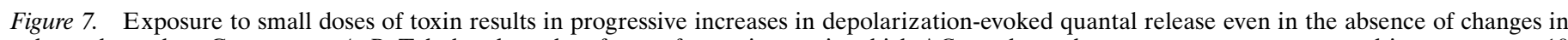

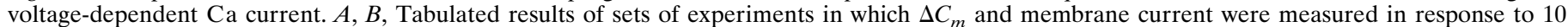

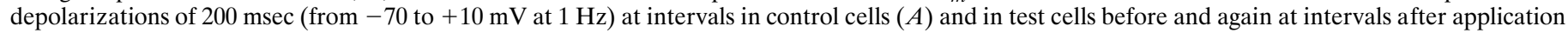

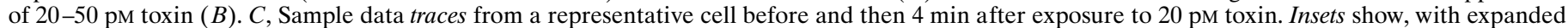

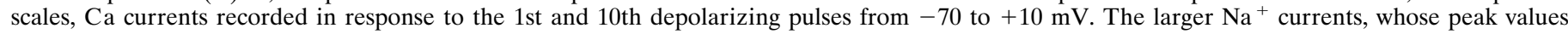
remained constant at $-820 \mathrm{pA}$, are truncated in these traces.

\section{Comparison of rates of toxin-enhanced spontaneous exocytosis with rates of asynchronous release after depolarization}

The results of the previous section suggested that at low doses LT enhances depolarization-evoked release at least in part by a mechanism independent of channel formation and enhancement of cytosolic $\mathrm{Ca}$. At higher doses of toxin, this alternative mechanism should work in parallel with channel formation to contribute to the massive enhancement of spontaneous exocytosis. To estimate the relative contributions of channel formation and the alternative mechanism to spontaneous exocytosis, we measured the $\mathrm{Ca}$ threshold and the rate of exocytosis at the higher cytosolic $\mathrm{Ca}$ that is seen during this mode of release and compared these values with those measured for "asynchronous" exocytosis occurring during and immediately after a train of depolarizing pulses. As shown in Figure 8, in response to a train of depolarizing pulses, an increasing fraction of evoked release occurs as a slow "creep" of capacitance, lasting up to several seconds after $\mathrm{Ca}$ entry has ceased, rather than an abrupt "step" in capacitance occurring "simultaneously" with (i.e., during or within a few milliseconds after) $\mathrm{Ca}$ entry. Although the step likely represents exocytosis of granules closely colocalized with $\mathrm{Ca}$ channels in response to a localized rise of $\mathrm{Ca}$ to many tens of micromoles per liter, the creep likely represents exocytosis of granules located up to several hundred nanometers from $\mathrm{Ca}$ channels in response to much lower levels of $\mathrm{Ca}$, even approximating the $\mathrm{Ca}$ concentration "equilibrated" over the bulk of the cytoplasm (Klingauf and Neher, 1997). It is likely that spontaneous exocytosis seen with toxin also represents fusion of granules poorly colocalized with the $\mathrm{Ca}$ entry site, because even when promoting massive $\mathrm{Ca}$ entry through single channels (see Fig. $5 B$ ), the toxin only enhances release after the average cytosolic $\mathrm{Ca}$ has risen to $\sim 1 \mu \mathrm{M}$.

Figure 9 shows our analysis of one of five experiments in which in the same cell we compared the $\mathrm{Ca}$ threshold and the rates of exocytosis at other cytosolic $\mathrm{Ca}$ levels that were seen with spontaneous toxin-enhanced exocytosis versus asynchronous exocytosis evoked by trains of depolarizations at two different frequencies. Note that both modes of exocytosis commence at similar 
pre-toxin
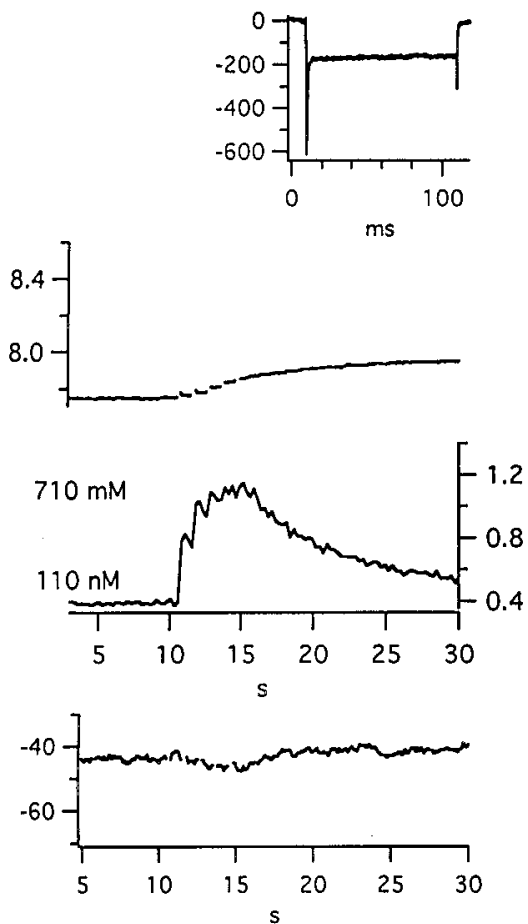

post-toxin (50 pM)
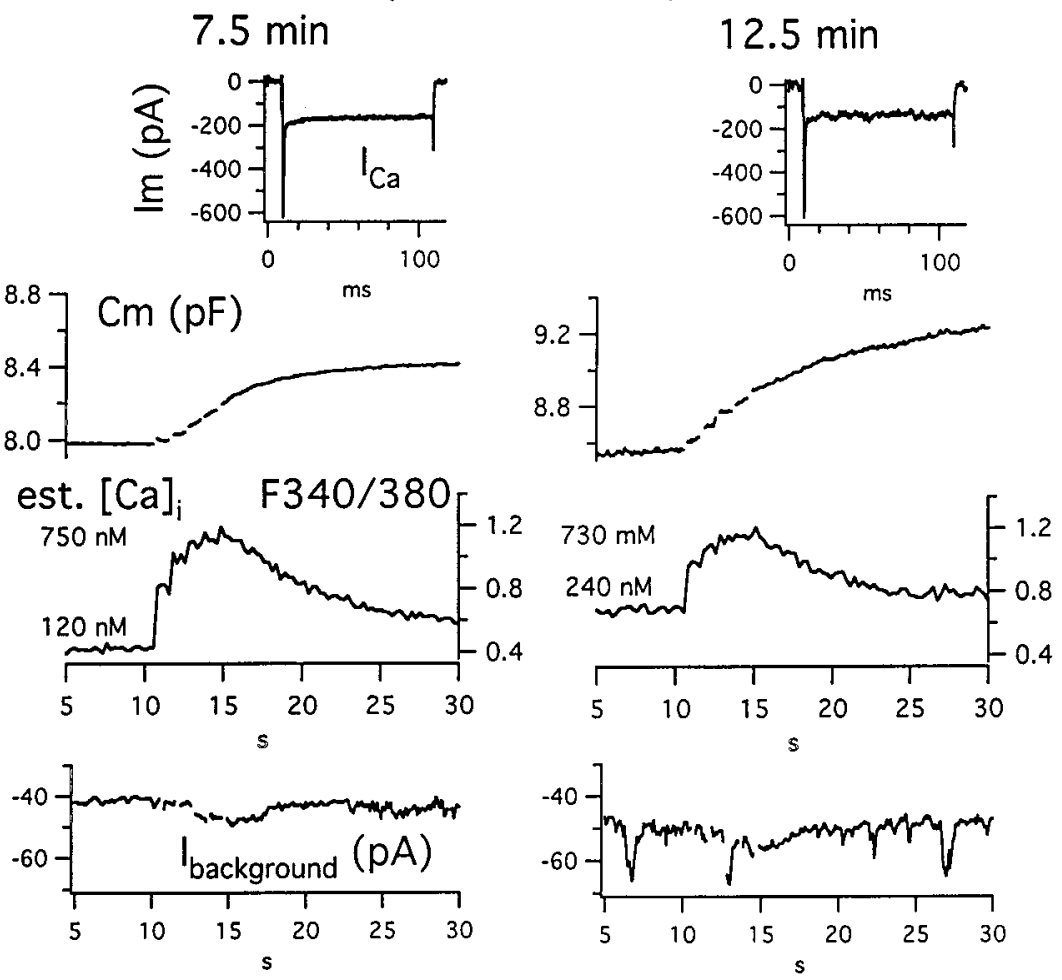

Figure 8. Simultaneous monitoring of effects of toxin on baseline and depolarization-evoked changes in membrane capacitance $\left(C_{m}\right)$ and cytosolic $\mathrm{Ca}$ (in this figure given as the ratio of fluorescence emission after excitation at 340 and $380 \mathrm{~nm}$, i.e., $\left.F_{340} / F_{380}\right)$. Background membrane current $\left(I_{\text {background }}\right.$ ) and depolarization-evoked currents are also shown. Left, Pretoxin data; Middle, Right, Post-toxin data at 7.5 and 12.5 min, respectively. Note that the 2.5 -fold increase in exocytotic response to the depolarizing train seen $7.5 \mathrm{~min}$ after addition of toxin is accompanied by a $<10 \%$ increase in background fluorescence ratio (and estimated cytosolic $\mathrm{Ca}$ ) and only a 5\% rise in the peak level of the fluorescence ratio (and estimated cytosolic Ca) over those in the control period. However, the further increase in exocytotic response observed at $12.5 \mathrm{~min}$ after addition of toxin occurs in the presence of a sustained rise in background cytosolic $\mathrm{Ca}$ but not in the peak level of cytosolic $\mathrm{Ca}$. In fact, at $12.5 \mathrm{~min}$, the summed Ca entry during the train was $\sim 20 \%$ less than that at $7.5 \mathrm{~min}$, because of the initially smaller Ca current and its faster "run-down" with repeated activity. The discrete steps seen in background current $\left(I_{\text {background }}\right)$ at 12.5 min most likely represent short-lived openings of toxin-induced ion channels. Note at each time point that the first $C_{m}$ response within the train was primarily a step-like change, whereas the responses to subsequent depolarizations took on a creeping component that at 7.5 and 12.5 min ultimately dominated the response and continued for several seconds.

cytosolic $\mathrm{Ca}$, here expressed as the ratio $F_{340} / F_{380}(0.45-0.5)$. However, at similar suprathreshold concentrations $\left(F_{340} / F_{380}\right.$ averaging 0.6) achieved at comparable times after the start of enhanced $\mathrm{Ca}$ entry, the rate of spontaneous exocytosis is fivefold faster than the rate of asynchronous exocytosis. In a series of five similar experiments, the rate of spontaneous exocytosis in response to the presence of toxin averaged $2.6 \pm 0.5$ fold greater than that of asynchronous depolarization-evoked exocytosis. These results suggest that although Ca entry is the critical factor in initiating toxin-enhanced spontaneous exocytosis, an alternative mechanism works to augment, by several fold, the effects of sustained Ca entry.

\section{DISCUSSION}

\section{Overview}

In this study we used the adrenal chromaffin cell as a "model" system to study the relationship of changes in membrane conductance and excitability to the well-known secretory effects of $\alpha$-latrotoxin, an excitatory neurotoxin. Combining membrane capacitance tracking with spectrofluorometry in the readily patchclamped chromaffin cell, we have found important new evidence implicating $\mathrm{Ca}^{2+}$ entry via toxin-induced channels and resultant $\mathrm{Ca}$ accumulation in the cytosol as a critical mechanism by which the toxin initiates the enhancement of spontaneous exocytosis routinely seen at concentrations of toxin in excess of 100 pM. We present other evidence indicating the ability of lower doses of toxin (20-50 pM) to enhance depolarization-evoked exocytosis even under conditions in which the toxin produces no background rise in cytosolic $\mathrm{Ca}$ or in readily apparent channels. By comparing rates of exocytosis seen during toxin-enhanced "spontaneous release" with those seen during asynchronous exocytosis evoked by trains of depolarizations that raise $\mathrm{Ca}$ to similar levels, we obtained evidence suggesting that an additional action of toxin greatly augments the effects of channel formation and $\mathrm{Ca}$ entry in sustaining toxin-enhanced spontaneous exocytosis. It is likely that this additional action involves the binding of toxin to a newly cloned G-protein-related toxin receptor (CIRL/latrophilin).

\section{Toxin-induced spontaneous exocytosis: dependence on Ca entry}

Our experiments examining ion channels induced by the toxin demonstrated that these channels have interesting and novel features. (1) They have a huge unitary conductance (up to 400 $\mathrm{pS})$. (2) They are highly selective for cations over anions $\left(E_{\mathrm{rev}}\right.$ shifts negatively by $15 \mathrm{mV}$ on dilution of PSS by 50\%) yet allow passage of bulky univalent cations such as NMDG. (3) They are 


\section{Depolarization-evoked "asynchronous" exocytosis}
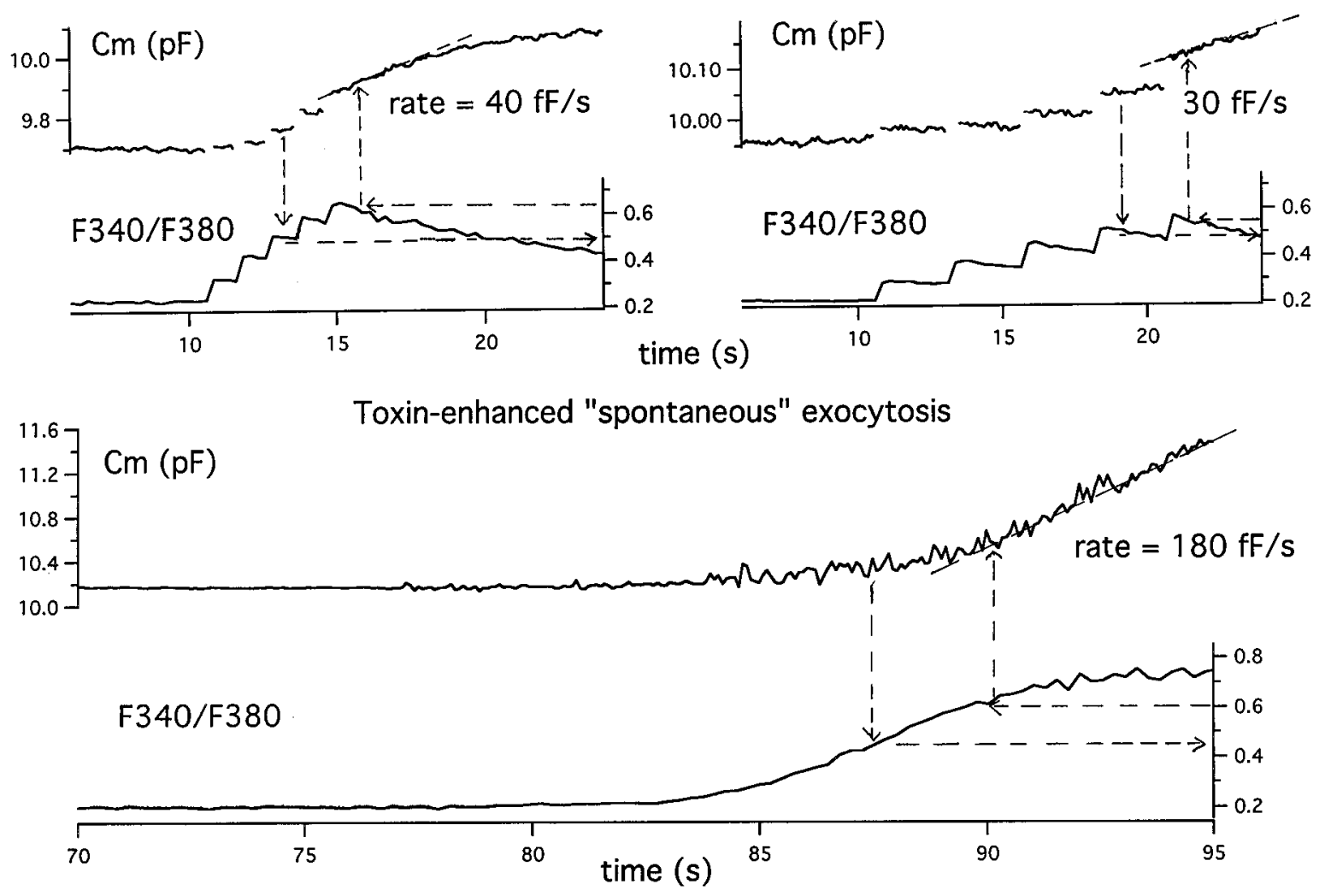

Figure 9. Toxin-enhanced spontaneous exocytosis has a similar threshold value of $[\mathrm{Ca}]_{\mathrm{i}}$ but occurs at a faster rate than does asynchronous exocytosis accompanying trains of depolarization measured in the same cell. Top, This cell was subjected to two trains of five $100 \mathrm{msec}$ depolarizations to $+10 \mathrm{mV}$, first at $1 \mathrm{~Hz}$ and later at $0.5 \mathrm{~Hz}$, and changes in $C_{m}$ and cytosolic Ca were monitored. Bottom, Then 1 nM toxin was added, and these parameters were again monitored. In the case of depolarization-evoked release, the Ca threshold was determined as the peak Ca level associated with the first response in the train to show distinct capacitance creep (see broken arrows downward and to the right). In the case of toxin-enhanced "spontaneous exocytosis," the $\mathrm{Ca}$ threshold was determined as the mean value of $\mathrm{Ca}$ over the range in which $C_{m}$ first averaged $100 \mathrm{fF}$ above a stable baseline. This criterion was chosen because in most experiments an increase in background membrane conductance caused by toxin was reflected as an increase in capacitance noise. The rate of capacitance increase at the suprathreshold concentration(s) was determined as the slope of the line tangent to the $C_{m}$ curve over the time interval corresponding to the designated cytosolic $\mathrm{Ca}$ range (see broken arrows to the left and upward). In the case of the asynchronous exocytosis, the $\mathrm{Ca}$ level chosen was the peak level at the end of the train. The average value obtained for the two runs shown was chosen as the Ca value for use with toxin-related release.

highly permeable to $\mathrm{Ca}$ (i.e., in isotonic-Ca PSS, inward currents seen at $-70 \mathrm{mV}$ were approximately one-third those in control PSS, whereas $E_{\text {rev }}$ was unchanged). Using a modified form of the Goldman-Hodgkin-Katz equation (Fatt and Ginsborg, 1958), we calculate that $P_{\mathrm{Ca}} / P_{\mathrm{Cs}}=0.6$. This work confirms and extends an earlier characterization of toxin-induced channels in neuroblastoma cells (Hurlbut et al., 1994).

Experiments examining cytosolic $\mathrm{Ca}$ levels simultaneously with exocytosis demonstrated that the initiation of toxinenhanced spontaneous exocytosis is attributable to the ability of membrane-bound $\alpha$-LT to form Ca-permeable channels through which $\mathrm{Ca}$ can enter into, and then accumulate within, the cytoplasm. In control PSS, as well as in isotonic-Ca PSS, exocytosis begins only after cytosolic free $\mathrm{Ca}$ has risen to 500-1000 nM. This "threshold value" of cytosolic Ca resembles that seen when patchclamped chromaffin cells are dialyzed with patch pipette solutions of known Ca concentration (Augustine and Neher, 1992). In isotonic-Ca PSS, in which the total toxin-induced inward current is carried by $\mathrm{Ca}$, the rise in $\mathrm{Ca}$ and the onset of secretion follow the sustained (several seconds long) opening of a single channel. Although there is a consistent delay in the onset of toxin-induced secretion after the opening of toxin-induced channels, secretion is continuous after it commences. This feature resembles the asynchronous exocytosis observed when chromaffin cells are subjected to prolonged electrical depolarization (Engisch and Nowycky, 1996; Barnett et al., 1997; Klingauf and Neher, 1997); the latter may reflect "loose colocalization" between sites of Ca entry and high affinity release-activating sites ( $K_{d}$ of several micromolar).

Several lines of evidence make it likely that $\mathrm{Ca}$ entry is occurring through a channel induced de novo by the toxin itself or by the toxin-liganded receptor. First, the conductance of the toxinrelated channel greatly exceeds that of native cation channels. Its estimated single-channel conductance of $130 \mathrm{pS}$ in isotonic external $\mathrm{Ca}$ far exceeds the largest conductance (20-25 pS) measured for an L-type Ca channel in isotonic $\mathrm{Ba}$ or for a stretchactivated nonselective cation channel in isotonic $\mathrm{Ca}(\sim 10 \mathrm{pS})$. Its estimated conductance of $400 \mathrm{pS}$ in divalent cation-free PSS far exceeds that of the $\mathrm{Ca}$ channels $(60 \mathrm{pS})$ or even stretch- or transmitter-activated, nonselective cation channels (40-60 pS) measured under similar conditions (see, for example, Hess et al., 1986). Second, toxin-induced channel activity and secretion persists even though voltage-dependent channels are pharmacologically blocked with TTX and Cd. Because the toxin induces channels with similar conductance and selectivity in planar bilay- 
ers lacking any protein receptors (Finkelstein et al., 1976), it is likely that the toxin itself is the critical channel-forming agent.

\section{Is there a role for an action of toxin that is independent of channel forming ability?}

Contribution to toxin-enhancement of depolarization-evoked release?

We have also shown that low concentrations of $\alpha$-LT, incapable of supporting massive spontaneous quantal release, do enhance release evoked by repetitive depolarization. Mechanistically, enhancement of evoked quantal release might occur in a Ca entrydependent manner, namely, if the toxin provided a "parallel pathway" for Ca entry, thereby transiently or persistently raising cytosolic $\mathrm{Ca}^{2+}$. Alternatively it might occur in a manner independent of toxin-induced $\mathrm{Ca}$ entry, especially if the transmembrane or cytoplasmic domain(s) of a toxin-activated receptor interacted directly with the secretory apparatus to enhance release. Candidate substrates for these interactions are now plentiful. In vitro, synaptotagmin, the putative $\mathrm{Ca}$ receptor in $\mathrm{Ca}$ dependent secretion, binds to a neurexin-like receptor for $\alpha$-LT, whereas syntaxin, a putative key component of the granule docking and fusion complex, binds CIRL/latrophilin, the presumed G-protein-coupled receptor for $\alpha$-LT.

Our observations that enhancement by toxin of depolarizationevoked release can occur in the absence of demonstrable toxininduced channel activity and a sustained increase in cytosolic $\mathrm{Ca}$ is consistent with a mechanism of action independent of channel formation. An interesting possibility is that toxin increases the size of the readily releasable pool of granules (RRP). A Gprotein-coupled receptor might activate an effector system such as protein kinase $\mathrm{C}$, whose enhanced activity might increase the RRP (Gillis et al., 1996). Other possibilities are a change in Ca sensitivity of release or a change in $\mathrm{Ca}$ handling by sequestration or extrusion machinery, either of which might be caused by interaction of a liganded toxin receptor with another aspect of the secretory apparatus. Those possibilities are worth extensive further investigation. To be sure, an important caveat is that based on our noncontinuous recording, we cannot rule out the occurrence of transient bursts of channel activity resulting in $\mathrm{Ca}$ induced enhancement of the RRP. However, a comparison of the rates of toxin-enhanced spontaneous exocytosis and asynchronous exocytosis occurring during repetitive depolarization provides additional evidence in favor of a mechanism independent of channel formation.

\section{Contribution to spontaneous release?}

As discussed above, it is reasonable to assume that the sustained asynchronous exocytosis evoked by repetitive depolarization and the toxin-enhanced spontaneous exocytosis, both of which are dependent on $\mathrm{Ca}$ entry but slow-to-start thereafter, result from granule fusions at sites distant from $\mathrm{Ca}$ entry that better reflect global rather than highly localized cytosolic Ca concentrations. If so, both release patterns should require a similar threshold concentration of cytosolic $\mathrm{Ca}$ to commence. Our data, although limited, suggest this is so. However, curiously, even when the rises in cytosolic $\mathrm{Ca}$ develop over similar time courses, the rates of secretion caused by the toxin are several times higher, suggesting that the toxin exerts some action in addition to raising cytosolic Ca. Two other recent sets of evidence support this idea. (1) Toxin can increase release evoked in detergent-permeabilized cells by a fixed concentration of extracellular Ca (Bittner et al., 1998), and (2) toxin can enhance release evoked by application of a fixed concentration of cholinergic agonist without altering the global cytosolic $\mathrm{Ca}$ transient evoked by the agonist (Michelena et al., 1997).

\section{Conclusions}

These results suggest that there may be at least two modes of toxin action. One, operative at low doses, enhances exocytosis already stimulated by secretagogue levels of cytosolic $\mathrm{Ca}$; the other, operative at higher doses, itself insures that those secretagogue levels will be present. The former enhances depolarization-evoked quantal release, the predominant "regulated" mode of secretion in most excitable cells, and increases the potency of toxin enhancement of spontaneous exocytosis seen in the absence of ongoing electrical activity. The latter actually initiates the massive enhancement of spontaneous exocytosis seen at high doses of toxin.

\section{REFERENCES}

Artalejo CR, Henley JR, McNiven MA, Palfrey HC (1995) Rapid endocytosis coupled to exocytosis in adrenal chromaffin cells involves $\mathrm{Ca}^{2+}, \mathrm{GTP}$, and dynamin but not clathrin. Proc Natl Acad Sci USA 92:8328-8332.

Augustine GA, Neher E (1992) Calcium requirements for secretion in bovine chromaffin cells. J Physiol (Lond) 450:247-271.

Barnett DW, Misler S (1997) An optimized approach to membrane capacitance estimation using dual frequency excitation. Biophys $\mathrm{J}$ 72:1641-1658.

Barnett DW, Liu J, Misler S (1996) Single-cell measurements of quantal secretion induced by rat adrenal chromaffin cells: dependence on extracellular $\mathrm{Ca}^{2+}$. Pflügers Arch 432:1039-1046.

Barnett DW, Liu J, Misler S (1997) Depolarization-induced asynchronous release from rat adrenal chromaffin cells. Biophys J 72:A157.

Barry PH, Lynch JW (1991) Liquid junction potentials and small cell effects in patch-clamp analysis. J Membr Biol 121:101-117.

Bennett MK, Scheller RH (1994) A molecular description of synaptic vesicle membrane trafficking. Annu Rev Biochem 63:63-100.

Bittner M, Krasnoperov VG, Stuenkel EL, Petrenko AG, Holz RW (1998) $\mathrm{A} \mathrm{Ca}^{2+}$-independent receptor for latrotoxin, CIRL, mediates effects on secretion via multiple mechanisms. J Neurosci 18:2914-2922.

Bittner MA, Das Gupta BR, Holz RW (1989) Isolated light chains of botulinum toxin inhibit exocytosis. Studies in digitonin-permeabilized chromaffin cells. J Biol Chem 264:10354-10360.

Chow RH, von Rueden L, Neher E (1992) Delay in vesicle fusion revealed by electrochemical monitoring of single secretory events in adrenal chromaffin cells. Nature 356:60-63.

Chow RH, Klingauf J, Neher E (1994) Time course of $\mathrm{Ca}^{2+}$ concentration triggering exocytosis in neuroendocrine cells. Proc Natl Acad Sci USA 91:12765-12769.

Davletov BA, Shamotienko OG, Lelianova VG, Grishkin EV, Ushkaryov YA (1996) Isolation and biochemical characterization of a $\mathrm{Ca}^{2+}$ independent $\alpha$-latrotoxin-binding protein. J Biol Chem 271: 23239-23245.

Dunn LA, Holz RW (1983) Catecholamine secretion from digitonintreated adrenal medullary chromaffin cells. J Biol Chem 258: 4989-4993.

Engisch KL, Nowycky MC (1996) Calcium dependence of large densecored vesicle exocytosis evoked by calcium influx in bovine adrenal chromaffin cells. J Neurosci 16:1359-1369.

Fatt P, Ginsborg BL (1958) The ionic requirements for the production of action potentials in crustacean muscle fibres. J Physiol (Lond) 142:516-543.

Finkelstein A, Rubin LL, Tzeng MC (1976) Black widow spider venom: effect of purified toxin on lipid bilayer membranes. Science 193:1009-1011.

Gillis KD, Moessner R, Neher E (1996) Protein kinase C enhances exocytosis from chromaffin cells by increasing the size of the readily releasable pool of secretory granules. Neuron 16:1209-1220.

Grynkiewicz G, Poenie M, Tsien RY (1985) A new generation of $\mathrm{Ca}^{2+}$ indicators with greatly improved fluorescence properties. J Biol Chem 260:3440-3450 
Heinemann C, Rueden LV, Chow RH, Neher E (1993) A two-step model of secretion control in neuroendocrine cells. Pflügers Arch 424:105-112.

Hess P, Lansman JB, Tsien RW (1986) Calcium channel selectivity for divalent and monovalent cations. Voltage and concentration dependence of single channel current in ventricular heart cells. J Gen Physiol 88:293-319.

Hurlbut WP, Ceccarelli B (1979) Use of black widow spider venom to study the release of neurotransmitters. In: Neurotoxins, tools in neurobiology (Ceccarelli B, Clementi F, eds), pp 87-115. New York: Raven.

Hurlbut WP, Chieregatti E, Valtorta F, Haimann C (1994) $\alpha$-Latrotoxin channels in neuroblastoma cells. J Membr Biol 138:91-102.

Klingauf J, Neher E (1997) Modeling buffered $\mathrm{Ca}^{2+}$ diff usion near the membrane: implications for secretion in neuroendocrine cells. Biophys J 72:674-690.

Krasnoperov VG, Beavis R, Chepurny OG, Little AR, Plotnikov AN, Petrenko AG (1996) The calcium-independent receptor of alphalatrotoxin is not a neurexin. Biochem Biophys Res Commun 227:868-875.

Littleton JT, Bellen HJ (1995) Synaptotagmin controls and modulates synaptic-vesicle fusion in a $\mathrm{Ca}^{2+}$-dependent manner. Trends Neurosci 18:177-183.

Liu J, Misler S (1998a) Alpha-latrotoxin alters spontaneous and depolarization evoked quantal release from rat adrenal chromaffin cells. Biophys J 74:A95.

Liu J, Misler S (1998b) $\alpha$-Latrotoxin-induced quantal release of catecholamines from rat adrenal chromaffin cells. Brain Res 799:56-64.

Longenecker HE, Hurlbut WP, Mauro A, Clark AW (1970) Effects of black widow spider venom on the frog neuromuscular junction. Nature 225:701-703.

Meldolesi J, Madeddu L, Torda M, Gatti G, Niutta E (1983) The effect of $\alpha$-latrotoxin on the neurosecretory PC12 cell line: studies on toxin binding and stimulation of transmitter release. Neuroscience 10:997-1009.

Michelena P, de la Fuente MT, Vega T, Lara B, Lopez MG, Gandia L, Garcia AG (1997) Drastic facilitation by $\alpha$-latrotoxin of bovine chromaffin cell exocytosis without measurable enhancement of $\mathrm{Ca}^{2+}$ entry or $\left[\mathrm{Ca}^{2+}\right]_{i}$. J Physiol (Lond) 502:481-496.

Misler S, Hurlbut WP (1979) Action of black widow spider venom on quantized release of acetylcholine at the frog neuromuscular junction: dependence upon external $\mathrm{Mg}^{2+}$. Proc Natl Acad Sci USA 76:991-995.

Neely A, Lingle CJ (1992) Two components of calcium-activated potassium current in rat adrenal chromaffin cells. J Physiol (Lond) 453:97-131.

Neher E (1992) Correction for liquid junction potentials in patch clamp experiments. Methods Enzymol 207:123-131.

Neher E, Marty A (1982) Discrete changes of cell membrane capacitance observed under conditions of enhanced secretion in bovine adrenal chromaffin cells. Proc Natl Acad Sci USA 79:6712-6716.

Nicholls DG, Rugolo M, Scott IG, Meldolesi J (1982) $\alpha$-Latrotoxin of black widow spider venom depolarizes the plasma membrane, induces massive calcium influx and stimulates transmitter release in guinea pig brain synaptosomes. Proc Natl Acad Sci USA 79:7924-7928.

Petrenko AG (1993) $\alpha$-Latrotoxin receptor. Implications in nerve terminal function. FEBS Lett 325:81-85.

Petrenko AG, Perin MS, Davletov BA, Ushkaryov YA, Geppert M, Suedhof TC (1991) Binding of synaptotagmin to the $\alpha$-latrotoxin receptor implicates both in synaptic vesicle exocytosis. Nature 353:65-68.

Rosenthal L, Meldolesi J (1989) $\alpha$-Latrotoxin and related toxins. Pharmacol Ther 42:115-134.

Smith C, Neher E (1997) Multiple forms of endocytosis in bovine adrenal chromaffin cells. J Cell Biol 139:885-894.

Ushkaryov YA, Petrenko AG, Geppert M, Suedhof TC (1992) Neurexins: synaptic cell surface proteins related to the $\alpha$-latrotoxin receptor and laminin. Science 257:50-56.

von Rueden L, Neher E (1993) A Ca-dependent early step in the release of catecholamines from adrenal chromaffin cells. Science 262:1061-1065.

Wightman RM, Jankowski JA, Kennedy RT, Kawagoe KT, Schroeder TJ, Leszczyszyn DJ, Near JA, Diliberto Jr EJ, Viveros OH (1991) Temporally resolved catecholamine spikes correspond to single vesicle release from individual chromaffin cells. Proc Natl Acad Sci USA 88:10754-10758.

Zhou Z, Misler S (1995) Amperometric detection of stimulus-induced quantal release of catecholamines from cultured superior cervical ganglion neurons. Proc Natl Acad Sci USA 92:6938-6942.

Zhou Z, Misler S (1996) Amperometric detection of quantal secretion from patch-clamped rat pancreatic $\beta$-cells. J Biol Chem 271:270-277. 